Supporting Information

\title{
Poisoning-Resistant $\mathrm{NO}_{\mathrm{x}}$ Reduction in the Presence of Alkaline and Heavy Metals over H-SAPO-34-Supported Ce-Promoted Cu-Based Catalysts
}

Penglu Wang, ${ }^{a \dagger}$ Lijun Yan, ${ }^{\mathrm{a} \dagger}$ Yundong Gu, ${ }^{\mathrm{a}}$ Sanchai Kuboon, ${ }^{\mathrm{b}}$ Hongrui Li, ${ }^{\mathrm{a}}$ Tingting Yan, ${ }^{\mathrm{a}}$ Liyi Shi, ${ }^{\mathrm{a}}$ and Dengsong Zhang*a

a Department of Chemistry, Research Center of Nano Science and Technology, School of Environmental and Chemical Engineering, Shanghai University, Shanghai 200444, P. R. China.

${ }^{b}$ National Nanotechnology Center, National Science and Technology Development Agency, 111 Thailand Science Park, Pathum Thani 12120, Thailand.

${ }^{\dagger}$ These authors contributed equally to this work.

*To whom correspondence should be addressed:

Tel: +86-21-66137152; E-mail: dszhang@shu.edu.cn.

The Supporting Information includes 43 pages, 25 figures, and 3 tables. 


\section{Table of Contents}

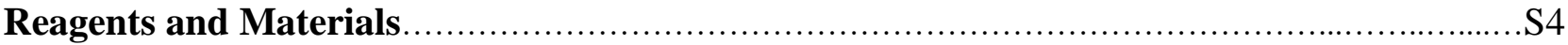

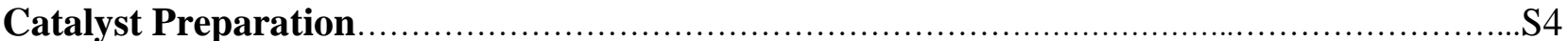

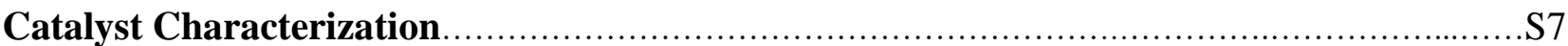

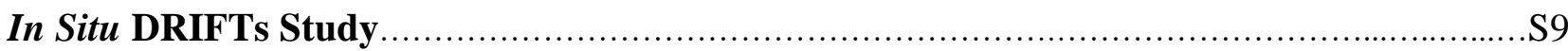

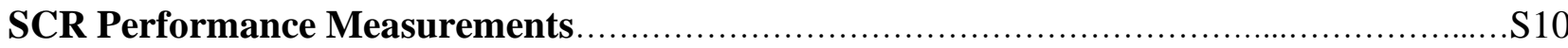

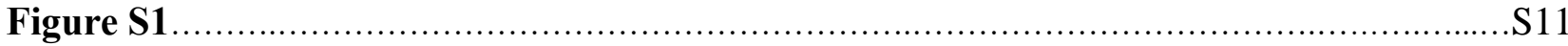

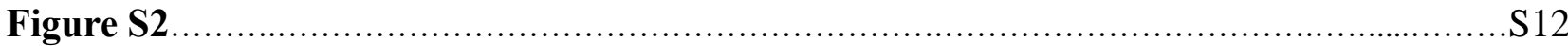

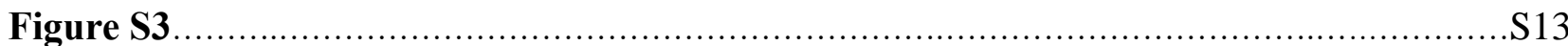

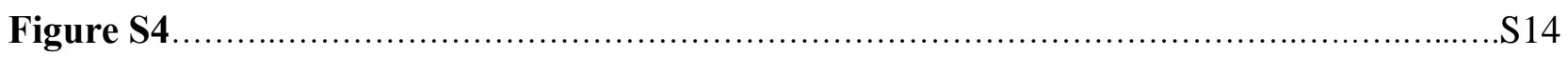

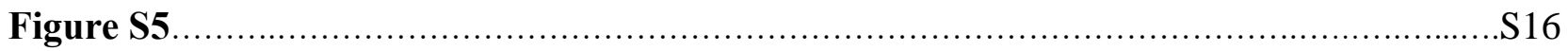

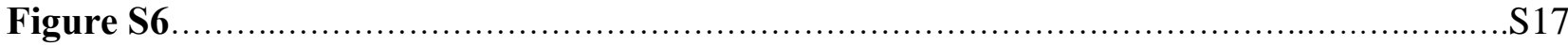

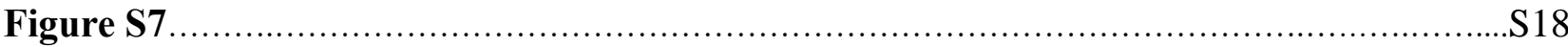

Figure S8

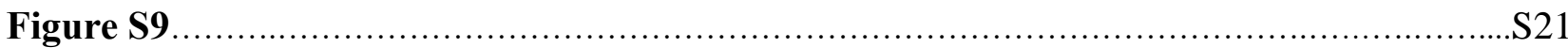

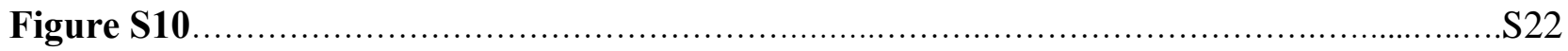

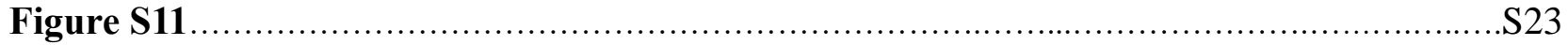

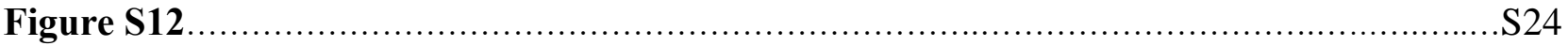

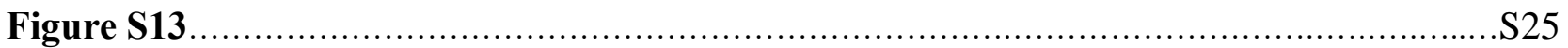

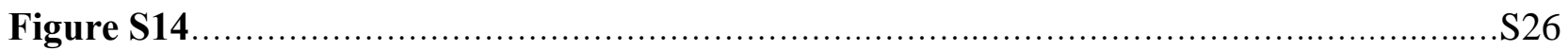

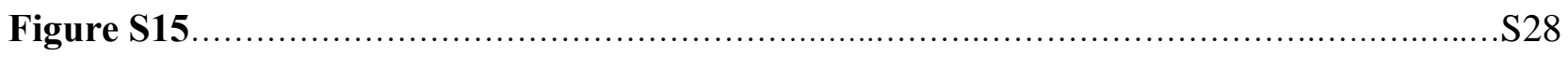

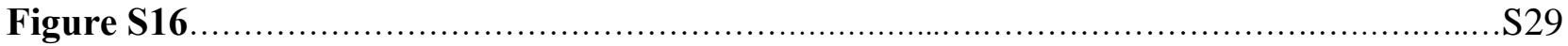

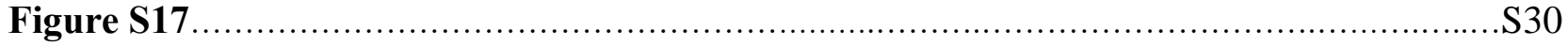

Figure S18

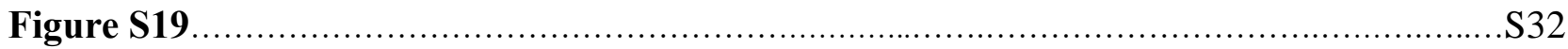


Figure S20.

. $\mathrm{S} 33$

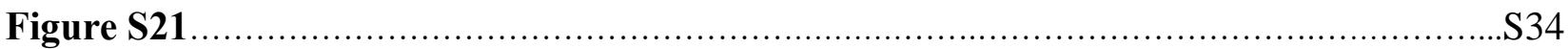

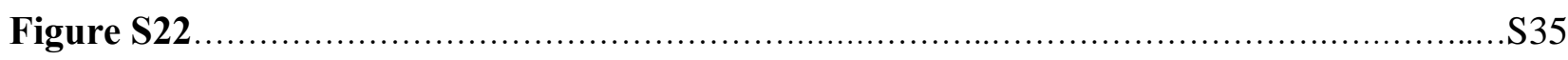

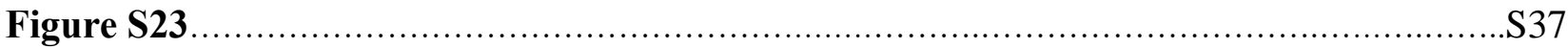

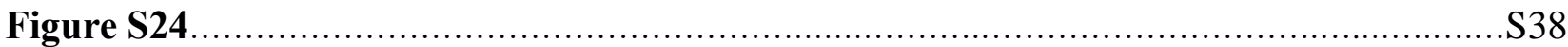

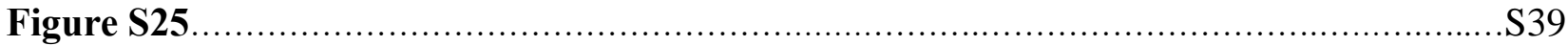

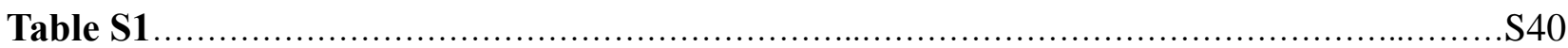

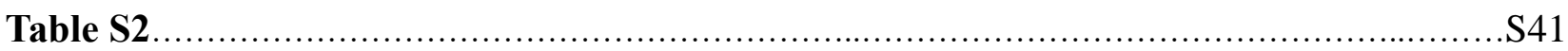

Table S3

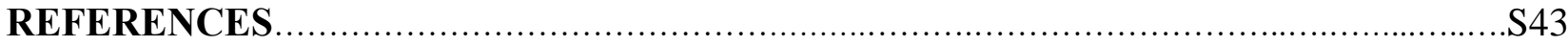




\section{Reagents and Materials}

All the reagents were used without further purification and purchased from Sinopharm Chemical Reagent Co. Ltd (China). The H-SAPO-34 were purchased from Tianjin Nankai University Catalyst Co., Ltd.

\section{Catalyst Preparation}

In a typical synthesis of $\mathrm{Cu}(\mathrm{x}) / \mathrm{H}-\mathrm{SAPO}-34$ or $\mathrm{CuCe}(\mathrm{y}) / \mathrm{H}-\mathrm{SAPO}-34, \mathrm{H}-\mathrm{SAPO}-34$ was first mixed with $50 \mathrm{~mL}$ aqueous solution containing certain amount of $\mathrm{Cu}\left(\mathrm{NO}_{3}\right)_{2} \cdot 3 \mathrm{H}_{2} \mathrm{O}$ or $\mathrm{Cu}\left(\mathrm{NO}_{3}\right)_{2} \cdot 3 \mathrm{H}_{2} \mathrm{O}$ and $\mathrm{Ce}\left(\mathrm{NO}_{3}\right)_{3} \cdot 6 \mathrm{H}_{2} \mathrm{O}$. Then, the mixture was evaporated at $45{ }^{\circ} \mathrm{C}$ using vacuum rotary evaporator, dried overnight, then calcined at $500{ }^{\circ} \mathrm{C}$ for $2 \mathrm{~h}$. As for the $\mathrm{Cu}(\mathrm{E}) \mathrm{Ce}(\mathrm{I}) / \mathrm{H}-\mathrm{SAPO}-34$ preparation, $\mathrm{H}-\mathrm{SAPO}-$ 34 was first pretreated by $0.1 \mathrm{M} \mathrm{NH}_{4} \mathrm{Cl}$ solution at $70{ }^{\circ} \mathrm{C}$ for $4 \mathrm{~h}$. After washing, drying, the $\mathrm{NH}_{4}$ SAPO-34 was dispersed into $50 \mathrm{~mL}$ aqueous solution containing certain amount of $\mathrm{Cu}\left(\mathrm{NO}_{3}\right)_{2} \cdot 3 \mathrm{H}_{2} \mathrm{O}$. Within $\mathrm{Cu}$ ion-exchange process completed, the $\mathrm{Cu}(\mathrm{E}) / \mathrm{H}-\mathrm{SAPO}-34$ material was washed, dried, and lastly mixed with an aqueous solution containing certain amount of $\mathrm{Ce}\left(\mathrm{NO}_{3}\right)_{3} \cdot 6 \mathrm{H}_{2} \mathrm{O}$. Then, the mixture was evaporated at $45^{\circ} \mathrm{C}$, dried overnight, and then calcined at $500^{\circ} \mathrm{C}$ for $2 \mathrm{~h}$. Apart from the synthesis of $\mathrm{Cu}(\mathrm{x}) / \mathrm{H}-\mathrm{SAPO}-34, \mathrm{CuCe}(\mathrm{y}) / \mathrm{H}-\mathrm{SAPO}-34$ and $\mathrm{Cu}(\mathrm{E}) \mathrm{Ce}(\mathrm{I}) / \mathrm{H}-\mathrm{SAPO}-34$ catalysts, Ce/H-SAPO-34 was prepared via a one-step wet impregnation method to observe the catalytic performance of $\mathrm{Ce}$ species supported on H-SAPO-34. In detail, H-SAPO-34 was first mixed with $50 \mathrm{~mL}$ of an aqueous solution containing a certain amount of $\mathrm{Ce}\left(\mathrm{NO}_{3}\right)_{3} \cdot 6 \mathrm{H}_{2} \mathrm{O}$. Then, the mixture was evaporated at $45{ }^{\circ} \mathrm{C}$ using a vacuum rotary evaporator, dried overnight, and then calcined at $500{ }^{\circ} \mathrm{C}$ for $2 \mathrm{~h}$. Furthermore, $\mathrm{Cu}(\mathrm{E}) / \mathrm{H}-\mathrm{SAPO}-34$ and $\mathrm{Cu}(\mathrm{E}) \mathrm{Ce}(\mathrm{E}) / \mathrm{H}-\mathrm{SAPO}-34$ catalysts were also prepared via a one-step ionexchange process to investigate the difference of deNO $\mathrm{N}_{\mathrm{x}}$ performance between catalysts obtained from 
impregnation and ion-exchange methods. In more words, H-SAPO-34 was first pretreated by $0.1 \mathrm{M}$ $\mathrm{NH}_{4} \mathrm{Cl}$ solution at $70{ }^{\circ} \mathrm{C}$ for $4 \mathrm{~h}$. After washing, drying, the $\mathrm{NH}_{4}-\mathrm{SAPO}-34$ was dispersed into $50 \mathrm{~mL}$ aqueous solution containing certain amount of $\mathrm{Cu}\left(\mathrm{NO}_{3}\right)_{2} \cdot 3 \mathrm{H}_{2} \mathrm{O}$ or a mixed $50 \mathrm{~mL}$ aqueous solution containing certain amount of $\mathrm{Cu}\left(\mathrm{NO}_{3}\right)_{2} \cdot 3 \mathrm{H}_{2} \mathrm{O}$ and $\mathrm{Ce}\left(\mathrm{NO}_{3}\right)_{3} \cdot 6 \mathrm{H}_{2} \mathrm{O}$. Within $\mathrm{Cu}$ and $\mathrm{Ce}$ ion-exchange process completed, the mixture were washed, dried overnight, and then calcined at $500{ }^{\circ} \mathrm{C}$ for $2 \mathrm{~h}$.

Poisoned catalysts were prepared by impregnating fresh catalysts in aqueous solutions of $\mathrm{KNO}_{3}$, $\mathrm{Ca}\left(\mathrm{NO}_{3}\right)_{2} \cdot 4 \mathrm{H}_{2} \mathrm{O}$, or $\mathrm{Pb}\left(\mathrm{NO}_{3}\right)_{2}$, then dried overnight and calcined in air at $500{ }^{\circ} \mathrm{C}$ for $5 \mathrm{~h}$. The poisoned catalysts were denoted as zM-CuCe/H-SAPO-34, zM-Cu/H-SAPO-34, zM-Cu(E)Ce(I)/H-SAPO-34, where $z$ denoted the weight percent of poisons $(\mathrm{M}=\mathrm{K}, \mathrm{Ca}$, or $\mathrm{Pb})$.

$\mathrm{FeCe}(5) / \mathrm{H}-\mathrm{SAPO}-34, \mathrm{CoCe}(5) / \mathrm{H}-\mathrm{SAPO}-34, \mathrm{NiCe}(5) / \mathrm{H}-\mathrm{SAPO}-34$ were prepared via the same onestep wet impregnation method to demonstrate the specifically optimal SCR performance of $\mathrm{CuCe}(5) / \mathrm{H}-\mathrm{SAPO}-34$ catalyst and labelled as FeCe/H-SAPO-34, CoCe/H-SAPO-34, NiCe/H-SAPO34 thereafter. H-SAPO-34 was first mixed with $50 \mathrm{~mL}$ of an aqueous solution containing a certain amount of $\mathrm{Ce}\left(\mathrm{NO}_{3}\right)_{3} \cdot 6 \mathrm{H}_{2} \mathrm{O}$ and $\mathrm{Fe}\left(\mathrm{NO}_{3}\right)_{3} \cdot 9 \mathrm{H}_{2} \mathrm{O}$, or $\mathrm{Co}\left(\mathrm{NO}_{3}\right)_{2} \cdot 6 \mathrm{H}_{2} \mathrm{O}$, or $\mathrm{Ni}\left(\mathrm{NO}_{3}\right)_{2} \cdot 6 \mathrm{H}_{2} \mathrm{O}$, respectively. Then, the mixture was evaporated at $45^{\circ} \mathrm{C}$ using a vacuum rotary evaporator, dried overnight, and then calcined at $500{ }^{\circ} \mathrm{C}$ for $2 \mathrm{~h}$.

The commercial $\mathrm{V}_{2} \mathrm{O}_{5}-\mathrm{WO}_{3}-\mathrm{TiO}_{2}$ catalyst was prepared to directly compare the alkaline and heavy metals resistance. Firstly, certain amount of $\mathrm{NH}_{4} \mathrm{VO}_{3}$ was dissolved into an oxalic acid solution and then ammonium tungstate was added in this mixed solution. After that, certain amount of anatase $\mathrm{TiO}_{2}$ support was further dispersed into the mixture. Then, the mixture was evaporated at $45^{\circ} \mathrm{C}$ using a vacuum rotary evaporator, dried overnight, and then calcined at $500{ }^{\circ} \mathrm{C}$ for $2 \mathrm{~h}$. The weight percentage of $\mathrm{V}$ and $\mathrm{W}$ oxides species are fixed at $1 \mathrm{wt} \%$ and $5 \mathrm{wt} \%$, respectively. Poisoned catalysts were 
prepared by impregnating fresh $\mathrm{V}_{2} \mathrm{O}_{5}-\mathrm{WO}_{3}-\mathrm{TiO}_{2}$ catalyst in aqueous solutions of $\mathrm{KNO}_{3}$, $\mathrm{Ca}\left(\mathrm{NO}_{3}\right)_{2} \cdot 4 \mathrm{H}_{2} \mathrm{O}$, or $\mathrm{Pb}\left(\mathrm{NO}_{3}\right)_{2}$, then dried overnight and calcined in air at $500{ }^{\circ} \mathrm{C}$ for $5 \mathrm{~h}$. The poisoned catalysts were denoted as $\mathrm{zM}-\mathrm{V}_{2} \mathrm{O}_{5}-\mathrm{WO}_{3}-\mathrm{TiO}_{2}$, where $z$ denoted the weight percent of poisons $(\mathrm{M}=$ $\mathrm{K}, \mathrm{Ca}$, or $\mathrm{Pb})$.

$\mathrm{Cu} / \mathrm{TiO}_{2}$ and $\mathrm{CuCe} / \mathrm{TiO}_{2}$ were prepared to clarify the unique property of H-SAPO-34 support. In detail, anatase $\mathrm{TiO}_{2}$ was first mixed with $50 \mathrm{~mL}$ of an aqueous solution containing a certain amount of $\mathrm{Cu}\left(\mathrm{NO}_{3}\right)_{2} \cdot 3 \mathrm{H}_{2} \mathrm{O}$ or $\mathrm{Cu}\left(\mathrm{NO}_{3}\right)_{2} \cdot 3 \mathrm{H}_{2} \mathrm{O}$ and $\mathrm{Ce}\left(\mathrm{NO}_{3}\right)_{3} \cdot 6 \mathrm{H}_{2} \mathrm{O}$ together. Then, the mixture was evaporated at $45{ }^{\circ} \mathrm{C}$ using a vacuum rotary evaporator, dried overnight, and then calcined at $500{ }^{\circ} \mathrm{C}$ for $2 \mathrm{~h}$.

To further demonstrate the effect of abundant Brønsted acid sites exist in the H-SAPO-34 support on the alkaline and heavy metal resistance, the H-SAPO-34 support was ion-exchanged by K ions to replace the $\mathrm{H}$ atoms. In detail, the $\mathrm{H}-\mathrm{SAPO}-34$ support was dispersed in a $50 \mathrm{ml}$ of $0.1 \mathrm{M} \mathrm{KCl}$ solution and stirred at $70{ }^{\circ} \mathrm{C}$ for $4 \mathrm{~h}$. After washing, drying, the K-SAPO-34 was dispersed into $50 \mathrm{~mL}$ of an aqueous solution containing a certain amount of $\mathrm{Cu}\left(\mathrm{NO}_{3}\right)_{2} \cdot 3 \mathrm{H}_{2} \mathrm{O}$ and $\mathrm{Ce}\left(\mathrm{NO}_{3}\right)_{3} \cdot 6 \mathrm{H}_{2} \mathrm{O}$. Then, the mixture was evaporated at $45^{\circ} \mathrm{C}$ using a vacuum rotary evaporator, dried overnight, and then calcined at $500{ }^{\circ} \mathrm{C}$ for $2 \mathrm{~h}$. 


\section{Catalyst Characterization}

The microstructure of catalyst was observed by transmission electron microscopy (JEM-200CX) and high-power transmission electron microscopy (JEM-2100F). The samples were degassed at $300{ }^{\circ} \mathrm{C}$ for $12 \mathrm{~h}$ before nitrogen adsorption. X-ray diffraction (XRD) measurements were performed on an X-ray diffractometer (Rigaku D/MAS-RB) with $\mathrm{Cu}-\mathrm{K \alpha}(40 \mathrm{kV}, 40 \mathrm{~mA})$ radiation, the $2 \theta$ angles were recorded in the range of $5^{\circ}$ to $60^{\circ}$ with a scan speed of $8^{\circ} / \mathrm{min}$. The elemental percentage was tested by the inductively coupled plasma atomic emission spectroscopy (ICP-AES), and the $10 \mathrm{mg}$ samples were dissolved in $10 \mathrm{ml}$ hydrofluoric acid before the test. The UV-Vis-NIR-DRS was collected using an Agilent Cary 5000 UV-Vis-NIR spectrometer equipped with a DRS accessory to allow collection in the diffuse reflectance mode, against a pure white reference standard. Spectra were collected between 200 and $800 \mathrm{~nm}$ with a data interval of $1 \mathrm{~nm}$ and at a rate of $200 \mathrm{~nm} / \mathrm{min}$. Electron paramagnetic resonance (EPR) experiments were carried out on a Bruker EMX-plus spectrometer. Powder samples $(\sim 15 \mathrm{mg})$ were contained in $4 \mathrm{~mm}$ OD quartz tubes. During spectral acquisition, microwave power was $200 \mathrm{~mW}$, and the frequency was $9.86 \mathrm{GHz}$. The field was swept $1500 \mathrm{G}$ in 84 s and modulated at $100 \mathrm{kHz}$ with a $5 \mathrm{G}$ amplitude. The X-ray photoelectron spectroscopy (XPS) system (PHI-5300) with $\mathrm{Mg}-\mathrm{K} \alpha$ radiation was used to detect the surface atomic concentration and element valence. The binding energies of $\mathrm{O}, \mathrm{Cu}$ and $\mathrm{Ce}$ were corrected for containment carbon peak $(\mathrm{C} 1 \mathrm{~s}=$ $284.6 \mathrm{eV}$ ) and the peak fitting was performed through the AugerScan software. Nitrogen adsorptiondesorption isotherms were measured at $77 \mathrm{~K}$ using a U.S. Quantachrome ASAP 2020M nitrogen adsorption instrument. The hydrogen temperature-programmed reduction $\left(\mathrm{H}_{2}-\mathrm{TPR}\right)$ was conducted on a Micromeritics AutoChem 2950 HP auto-adsorption apparatus with a thermal conductivity detector (TCD). Prior to the reduction process, $80 \mathrm{mg}$ of each catalyst was treated under Ar atmosphere with a 
flow rate of $30 \mathrm{ml} / \mathrm{min}$ at $300{ }^{\circ} \mathrm{C}$ for $30 \mathrm{~min}$, then cooled to room temperature under Ar atmosphere. In $\mathrm{H}_{2}$-TPR runs, the catalysts were exposed to $10 \% \mathrm{H}_{2} / \mathrm{Ar}$ and then the reactor temperature was raised from room temperature to $500{ }^{\circ} \mathrm{C}$ with a rate of $10{ }^{\circ} \mathrm{C} / \mathrm{min}$. The Micromeritics AutoChem $2950 \mathrm{HP}$ auto-adsorption apparatus was employed for $\mathrm{NH}_{3}$ temperature-programmed desorption $\left(\mathrm{NH}_{3}-\mathrm{TPD}\right)$ experiments with a TCD to monitor the $\mathrm{NH}_{3}$. Prior to the $\mathrm{NH}_{3}-\mathrm{TPD}$ experiments, $80 \mathrm{mg}$ catalysts were outgassed under He protection $(30 \mathrm{ml} / \mathrm{min})$ at $300{ }^{\circ} \mathrm{C}$ for $30 \mathrm{~min}$ and then cooled to $100{ }^{\circ} \mathrm{C}$. Samples were exposed to $4 \% \mathrm{NH}_{3} / \mathrm{He}$ for one hour at $100{ }^{\circ} \mathrm{C}$, the physical adsorption of ammonia was removed by $\mathrm{He}$ purging for $1 \mathrm{~h}$ at the same temperature. Finally, the temperature was raised to $500{ }^{\circ} \mathrm{C}$ with a ramping rate of $10{ }^{\circ} \mathrm{C} / \mathrm{min}$. The NO temperature-programmed desorption (NO-TPD) was carried out on a Tianjin XQ TP-5080 auto-adsorption apparatus with a TCD to monitor the $\mathrm{NO}_{\mathrm{x}}$ species. Similarly with the $\mathrm{NH}_{3}$-TPD experiment, $80 \mathrm{mg}$ catalysts were outgassed under He protection $(30 \mathrm{ml} / \mathrm{min})$ at $300{ }^{\circ} \mathrm{C}$ for $30 \mathrm{~min}$ and then cooled to $100{ }^{\circ} \mathrm{C}$. Samples were exposed to $2 \% \mathrm{NO} / \mathrm{N}_{2}$ for $1 \mathrm{~h}$ at $100{ }^{\circ} \mathrm{C}$, the physical adsorption of NO was removed by He purging for $1 \mathrm{~h}$ at the same temperature. Finally, the temperature was raised to $500{ }^{\circ} \mathrm{C}$ with a ramping rate of $10{ }^{\circ} \mathrm{C} / \mathrm{min}$. Pyridine-FTIR spectroscopy was performed by using a Nicolet iS50 FTIR spectrometer. The samples were pretreated at $300{ }^{\circ} \mathrm{C}$ for $0.5 \mathrm{~h}$ under vacuum condition to exclude physical adsorption and surface impurities. Then the background spectrum was collected at various target temperature to be deducted from the sample spectra. After that, the catalysts were adsorbed with pyridine at room temperature for $1 \mathrm{~h}$. The desorption process then went on under a flow of $\mathrm{N}_{2}$ and was recorded at corresponding temperatures. 


\section{In Situ DRIFTs Study}

In situ DRIFTs measurements were performed on a Nicolet 6700 spectrometer according to our previous publications ${ }^{1-4}$. All DRIFTs spectra were gathered in the wavenumber range of 3800 to 1000 $\mathrm{cm}^{-1}$ with the Kubelka-Munk format, accumulating 64 scans per minute at $4 \mathrm{~cm}^{-1}$ resolution. Prior to the experiment, each sample was pre-treated at $300{ }^{\circ} \mathrm{C}$ under $\mathrm{N}_{2}$ flow for $0.5 \mathrm{~h}$ and then regulated to the target temperature to obtain a background spectrum which should be deducted from the sample spectra. Furthermore, as for the adsorption-desorption of $\mathrm{NH}_{3}$ or $\mathrm{NO}+\mathrm{O}_{2}$ studies, after being pretreated at $300{ }^{\circ} \mathrm{C}$ and obtaining the background spectra of different temperatures, the catalysts were exposed to a flow of $500 \mathrm{ppm}$ of $\mathrm{NH}_{3}$ or $\mathrm{NO}+\mathrm{O}_{2}$ at $30{ }^{\circ} \mathrm{C}$ for $1 \mathrm{~h}$. The desorption process then went on under a flow of $\mathrm{N}_{2}$ and was recorded at corresponding temperatures. And for the transient reactions between $\mathrm{NO}+\mathrm{O}_{2}\left(\mathrm{NH}_{3}\right)$ and pre-adsorbed $\mathrm{NH}_{3}\left(\right.$ or $\left.\mathrm{NO}+\mathrm{O}_{2}\right)$, after the same pretreatment, the catalysts were exposed to $500 \mathrm{ppm} \mathrm{NH}_{3}$ (or $\mathrm{NO}+\mathrm{O}_{2}$ ) for the adsorption. Afterwards, the samples were purged by $\mathrm{N}_{2}$ and then introduced $\mathrm{NO}+\mathrm{O}_{2}\left(\right.$ or $\left.\mathrm{NH}_{3}\right)$ into the reactor. Meanwhile the reaction process was recorded as a function of time. 


\section{SCR Performance Measurements}

The $\mathrm{NH}_{3}-\mathrm{SCR}$ activity experiments were performed using $0.3 \mathrm{~g}$ catalysts ( $20-40$ mesh) in a fixed-bed reactor with an inner diameter of $8 \mathrm{~mm}$. The gas mixture composition was: $500 \mathrm{ppm} \mathrm{NO,} 500 \mathrm{ppm}$ $\mathrm{NH}_{3}, 5 \mathrm{vol} \% \mathrm{O}_{2}, 10 \mathrm{vol} \% \mathrm{H}_{2} \mathrm{O}$ (when used), $\mathrm{N}_{2}$ balance. The total flow rate was $265 \mathrm{ml} / \mathrm{min}$, and the gas hourly space velocity (GHSV) was $30000 \mathrm{~h}^{-1}$. The concentration of $\mathrm{NO}_{\mathrm{x}}, \mathrm{NH}_{3}$ and $\mathrm{N}_{2} \mathrm{O}$ at the

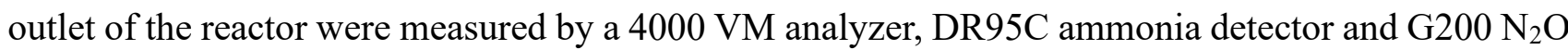
detector, respectively. The SCR catalytic activity was recorded after the reaction system reached a steady state. The NO conversion and $\mathrm{N}_{2}$ selectivity are calculated by the following equations:

NO conversion $(\%)=\frac{[\mathrm{NO}]_{\text {in }}-[\mathrm{NO}]_{\text {out }}}{[\mathrm{NO}]_{\text {in }}} \times 100 \%$

$\mathrm{N}_{2}$ selectivity $(\%)=\left(1-\frac{2\left[\mathrm{~N}_{2} \mathrm{O}\right]_{\text {out }}}{\left[\mathrm{NO}_{\mathrm{x}}\right]_{\text {in }}+\left[\mathrm{NH}_{3}\right]_{\text {in }}-\left[\mathrm{NO}_{\mathrm{x}}\right]_{\text {out }}-\left[\mathrm{NH}_{3}\right]_{\text {out }}}\right) \times 100 \%$

Where $\mathrm{NO}_{\mathrm{x}}$ stands for the total concentration of $\mathrm{NO}$ and $\mathrm{NO}_{2} \cdot[\mathrm{NO}]_{\text {in }},[\mathrm{NO}]_{\text {out }},\left[\mathrm{N}_{2} \mathrm{O}\right]_{\text {out }},\left[\mathrm{NO}_{\mathrm{x}}\right]_{\text {in }}$, $\left[\mathrm{NO}_{\mathrm{x}}\right]_{\text {out }},\left[\mathrm{NH}_{3}\right]_{\mathrm{in}}$, and $\left[\mathrm{NH}_{3}\right]_{\text {out }}$ indicate the corresponding inlet and outlet gas concentrations, respectively.

The GHSV is obtained by the following formula:

$\mathrm{GHSV}=\frac{\mathrm{q}_{\mathrm{v}}}{\pi \mathrm{hr} \mathrm{r}^{2}}$

$\mathrm{q}_{\mathrm{v}}$ corresponds to the total flow rate; $\mathrm{h}$ means the height of the catalyst in the reactor; and $\mathrm{r}$ represents the inner radius of the reactor.

The reaction rate $(r)$ was measured using the same conditions as for steady-state reaction and normalized on a per-sample weight basis using $\mathrm{NO}_{\mathrm{x}}$ conversion:

$r=F_{N O} * X_{N O} / 22.44 * W$

Where $F_{N O}$ is the concentration of inlet NO molecules $(\mathrm{L} / \mathrm{min}), W$ is the weight of the catalysts $(\mathrm{g})$, $X_{N O}$ is the NO conversion. 


\section{Figures and Tables}
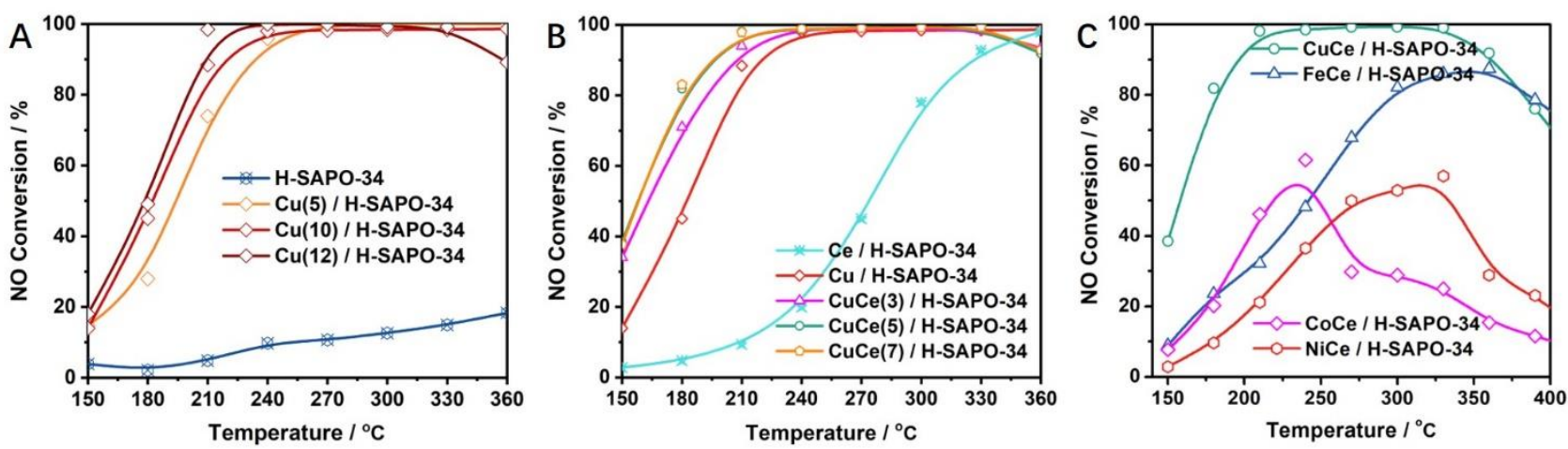

Figure S1. Plots of NO conversion as a function of reaction temperature for (A) H-SAPO-34 and $\mathrm{Cu}(\mathrm{x}) / \mathrm{H}-\mathrm{SAPO}-34$ catalysts, (B) Cu/H-SAPO-34, Ce/H-SAPO-34 and $\mathrm{CuCe}(\mathrm{y}) / \mathrm{H}-\mathrm{SAPO}-34$ catalysts and (C) $\mathrm{CuCe} / \mathrm{H}-\mathrm{SAPO}-34, \mathrm{FeCe} / \mathrm{H}-\mathrm{SAPO}-34, \mathrm{CoCe} / \mathrm{H}-\mathrm{SAPO}-34$ and NiCe/H-SAPO-34 catalysts. Reaction conditions: 500 ppm NO, $500 \mathrm{ppm} \mathrm{NH}_{3}, 5 \mathrm{vol} \% \mathrm{O}_{2}, \mathrm{~N}_{2}$ as the balance gas, GHSV of 30000 $\mathrm{h}^{-1}$.

Note: To investigate the effect of various amount of $\mathrm{Cu}$ species on the SCR performance, $\mathrm{Cu}(\mathrm{x}) / \mathrm{H}-$ SAPO-34 catalysts were also prepared via a wet impregnation method, where $\mathrm{x}(\mathrm{x}=5,10,12)$ represented the different weight amount of $\mathrm{Cu}$. As the $\mathrm{NO}$ conversion results shown in Figure S1A, lower loading amount of $\mathrm{Cu}(5) / \mathrm{H}-\mathrm{SAPO}-34$ catalyst cannot achieve the higher low temperature SCR activity as $\mathrm{Cu}(10) / \mathrm{H}-\mathrm{SAPO}-34$, while higher amount of $\mathrm{Cu}(12) / \mathrm{H}-\mathrm{SAPO}-34$ catalyst would result in declined high temperature activity which might be caused by the ammonia oxidation. Thus, the optimal content of $\mathrm{Cu}$ on $\mathrm{H}-\mathrm{SAPO}-34$ support in this study was fixed at $10 \mathrm{wt} \%$. 

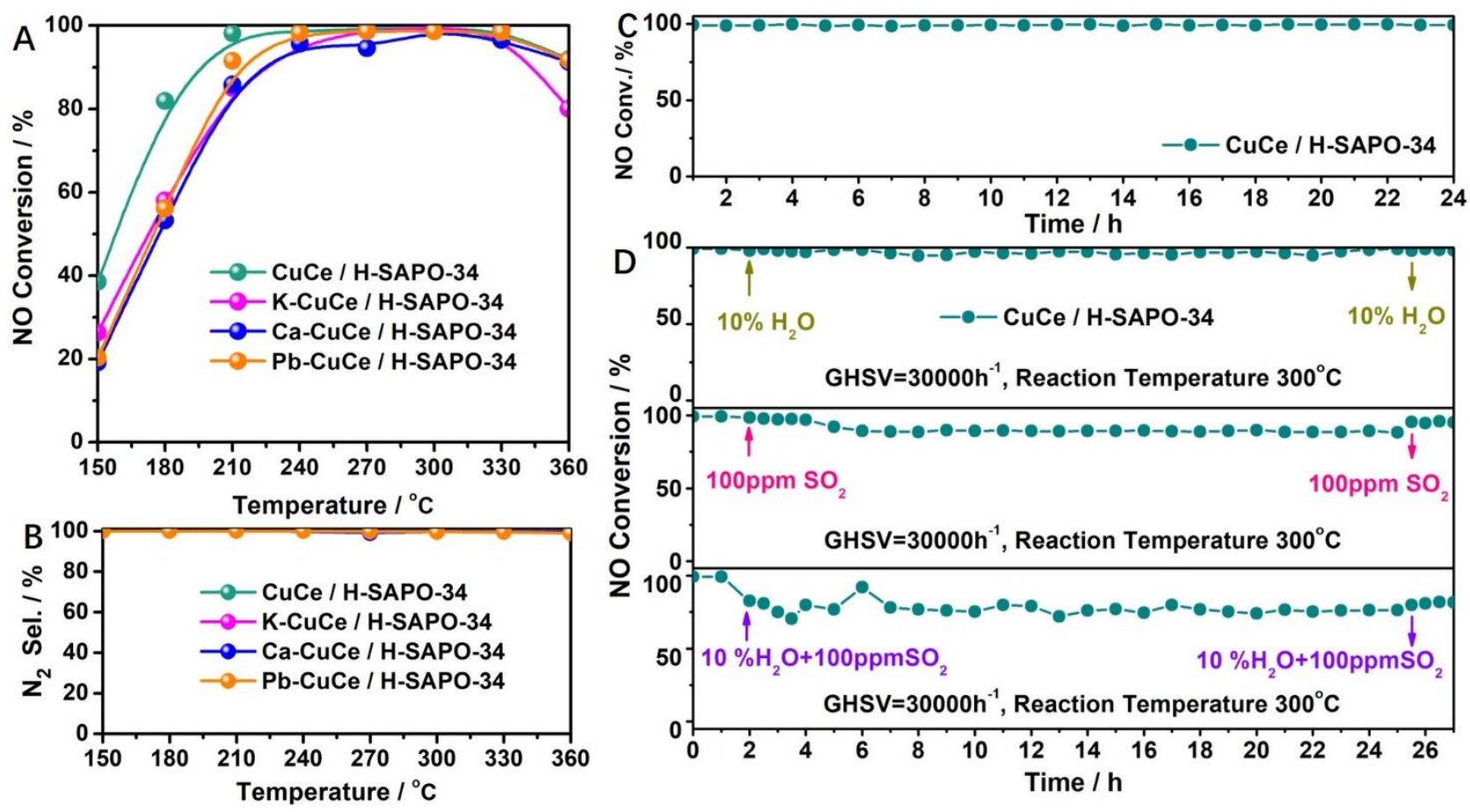

Figure S2. (A) Plots of NO conversion and (B) $\mathrm{N}_{2}$ selectivity as a function of reaction temperature for $\mathrm{CuCe} / \mathrm{H}-\mathrm{SAPO}-34$ and poisoned catalysts with $1 \mathrm{wt} \% \mathrm{~K}, \mathrm{Ca}$, or Pb addition. (C) Stability test of the $\mathrm{CuCe} / \mathrm{H}-\mathrm{SAPO}-34$ catalyst at $300{ }^{\circ} \mathrm{C}$ for $24 \mathrm{~h}$. (D) $\mathrm{H}_{2} \mathrm{O}$ durability, $\mathrm{SO}_{2}$ tolerance, $\mathrm{H}_{2} \mathrm{O}$ and $\mathrm{SO}_{2}$ cotolerance test of the $\mathrm{CuCe} / \mathrm{H}-\mathrm{SAPO}-34$ catalyst at $300{ }^{\circ} \mathrm{C}$ for $24 \mathrm{~h}$. Reaction conditions: $500 \mathrm{ppm} \mathrm{NO}$, $500 \mathrm{ppm} \mathrm{NH}_{3}, 5$ vol $\% \mathrm{O}_{2}, 10$ vol $\% \mathrm{H}_{2} \mathrm{O}$ (when used), $\mathrm{N}_{2}$ as the balance gas, GHSV of $30000 \mathrm{~h}^{-1}$. 

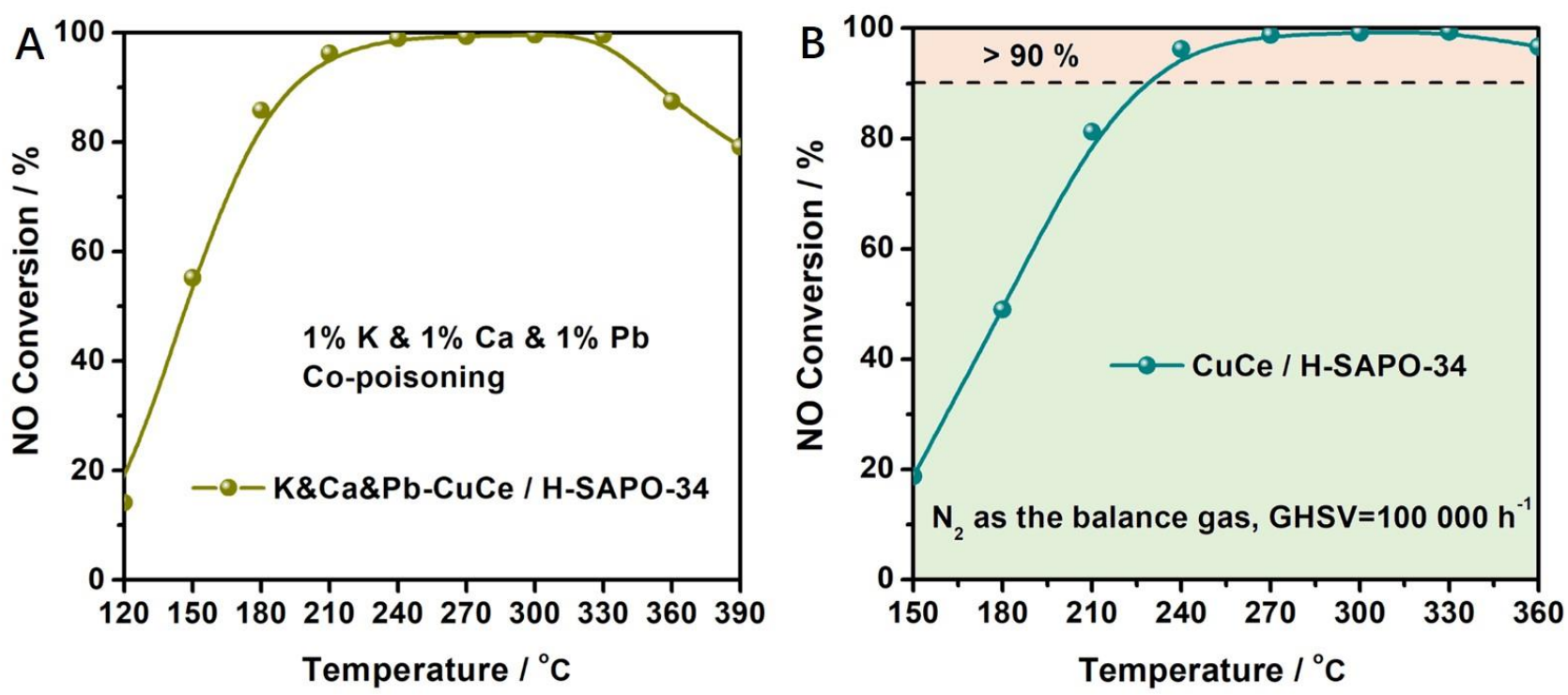

Figure S3. Plots of NO conversion as a function of reaction temperature for (A) CuCe/H-SAPO-34 catalyst with $1 \mathrm{wt} \% \mathrm{~K}, 1 \mathrm{wt} \% \mathrm{Ca}, 1 \mathrm{wt} \% \mathrm{~Pb}$ co-poisoned and (B) CuCe/H-SAPO-34 catalyst under $100000 \mathrm{~h}^{-1}$ GHSV. Reaction conditions: $500 \mathrm{ppm} \mathrm{NO}, 500 \mathrm{ppm} \mathrm{NH}_{3}, 5 \mathrm{vol}_{0} \mathrm{O}_{2}, \mathrm{~N}_{2}$ as the balance gas. 

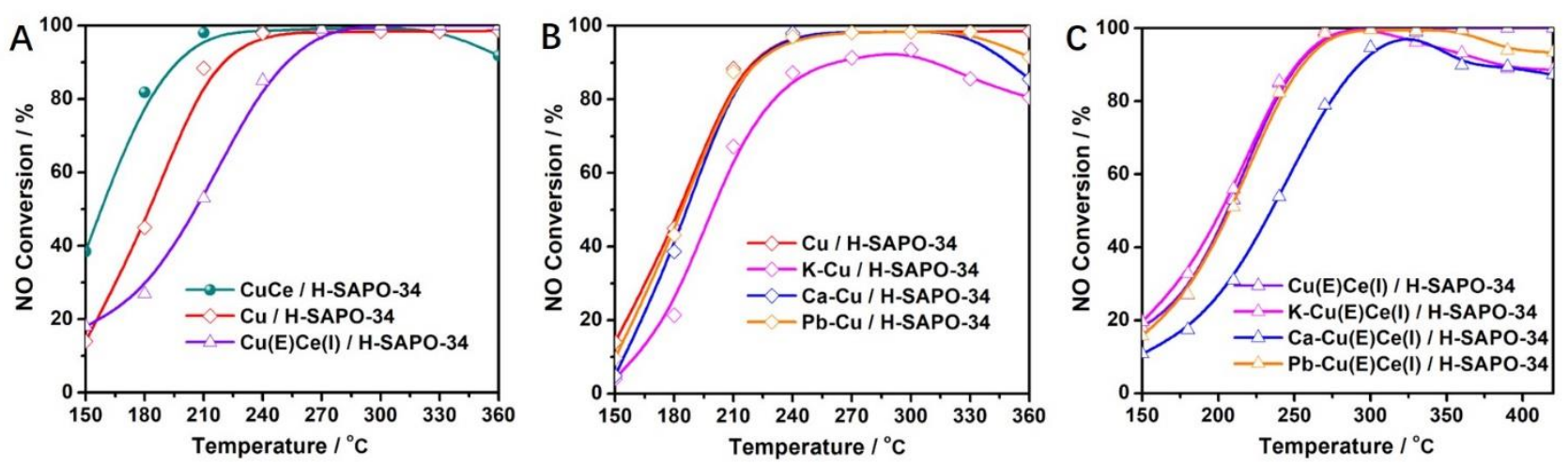

Figure S4. Plots of NO conversion as a function of reaction temperature for (A) CuCe/H-SAPO-34, Cu/H-SAPO-34, Cu(E)/H-SAPO-34, Cu(E)Ce(I)/H-SAPO-34, Cu(E)Ce(E)/H-SAPO-34 catalysts; (B) $\mathrm{Cu} / \mathrm{H}-\mathrm{SAPO}-34$ and $(\mathrm{C}) \mathrm{Cu}(\mathrm{E}) \mathrm{Ce}(\mathrm{I}) / \mathrm{H}-\mathrm{SAPO}-34$ catalysts in the presence of $1 \mathrm{wt} \% \mathrm{~K}, \mathrm{Ca}$, or $\mathrm{Pb}$. Reaction conditions: 500 ppm NO, $500 \mathrm{ppm} \mathrm{NH}_{3}, 5$ vol\% $\mathrm{O}_{2}, \mathrm{~N}_{2}$ as the balance gas, GHSV of 30000 $\mathrm{h}^{-1}$.

Note: Impregnated $\mathrm{Cu} / \mathrm{H}-\mathrm{SAPO}-34$ and ion-exchanged $\mathrm{Cu}(\mathrm{E}) / \mathrm{H}-\mathrm{SAPO}-34$ catalysts almost owned similar $\mathrm{NH}_{3}$-SCR activity except slight higher $\mathrm{NO}$ conversion of $\mathrm{Cu} / \mathrm{H}-\mathrm{SAPO}-34$ among $165-225{ }^{\circ} \mathrm{C}$ (Figure S4A). The difference was that after impregnated $\mathrm{Ce}$ species, $\mathrm{Cu}$ and $\mathrm{Ce}$ synchronously impregnated on the H-SAPO-34 support were more active than the exchanged $\mathrm{Cu}$ and impregnated $\mathrm{Ce}$ species. This phenomenon might result from that the $\mathrm{Cu}$ and $\mathrm{Ce}$ active sites could be simultaneously and highly dispersed on the H-SAPO-34 support for CuCe/H-SAPO-34, while the subsequent impregnated $\mathrm{Ce}$ sites would directly cover part of uniform exchanged $\mathrm{Cu}$ sites and also block the porous channel of $\mathrm{H}-\mathrm{SAPO}-34$ for $\mathrm{Cu}(\mathrm{E}) \mathrm{Ce}(\mathrm{I}) / \mathrm{H}-\mathrm{SAPO}-34$. Meanwhile, if the $\mathrm{Cu}$ and $\mathrm{Ce}$ were exchanged into the framework of H-SAPO-34 at the same time, the activity of $\mathrm{Cu}(\mathrm{E}) \mathrm{Ce}(\mathrm{E}) / \mathrm{H}-\mathrm{SAPO}-$ 34 was much worse than that of $\mathrm{Cu}(\mathrm{E}) \mathrm{Ce}(\mathrm{I}) / \mathrm{H}-\mathrm{SAPO}-34$. It might be caused that the differential ionexchange capacity of $\mathrm{Cu}$ and $\mathrm{Ce}$ ions cannot make sure their good dispersion and lose most of the active metal species to anchor with $\mathrm{H}-\mathrm{SAPO}-34$. Thus, only $\mathrm{Cu}$ and $\mathrm{Ce}$ species synchronously 
impregnated on the H-SAPO-34 support could maintain the effective active sites as much as possible and express highest $\mathrm{NH}_{3}$-SCR performance when take more than one metal phase into consideration. 

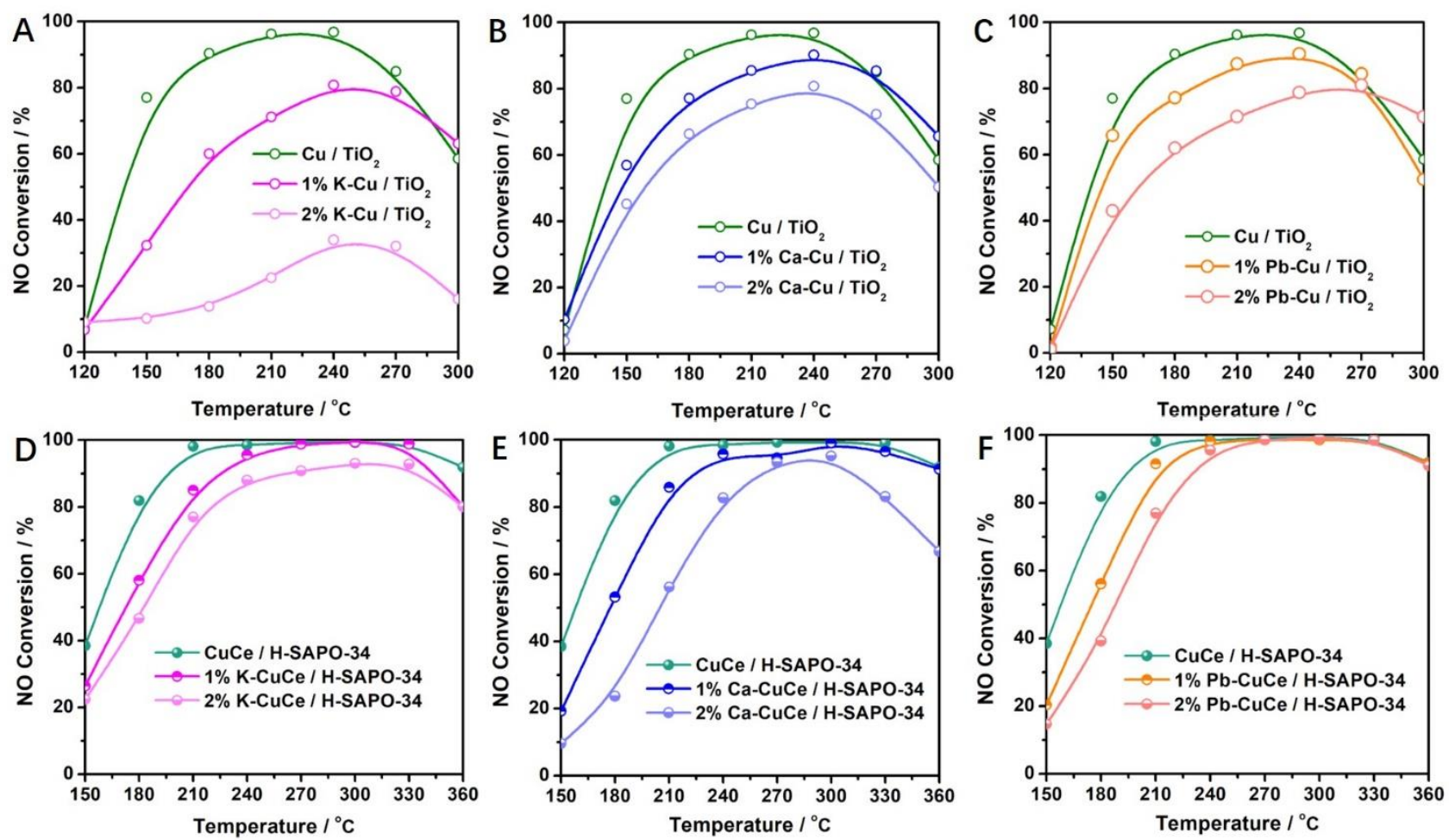

Figure S5. Plots of NO conversion as a function of reaction temperature for $(\mathrm{A}-\mathrm{C}) \mathrm{Cu} / \mathrm{TiO}_{2}$ and $(\mathrm{D}-\mathrm{F})$

$\mathrm{CuCe} / \mathrm{H}-\mathrm{SAPO}-34$ catalysts in the presence of $\mathrm{K}, \mathrm{Ca}$ and $\mathrm{Pb}$ with different amounts. Reaction conditions: 500 ppm NO, $500 \mathrm{ppm} \mathrm{NH}_{3}, 5 \mathrm{vol} \% \mathrm{O}_{2}, \mathrm{~N}_{2}$ as the balance gas, GHSV of $30000 \mathrm{~h}^{-1}$. 

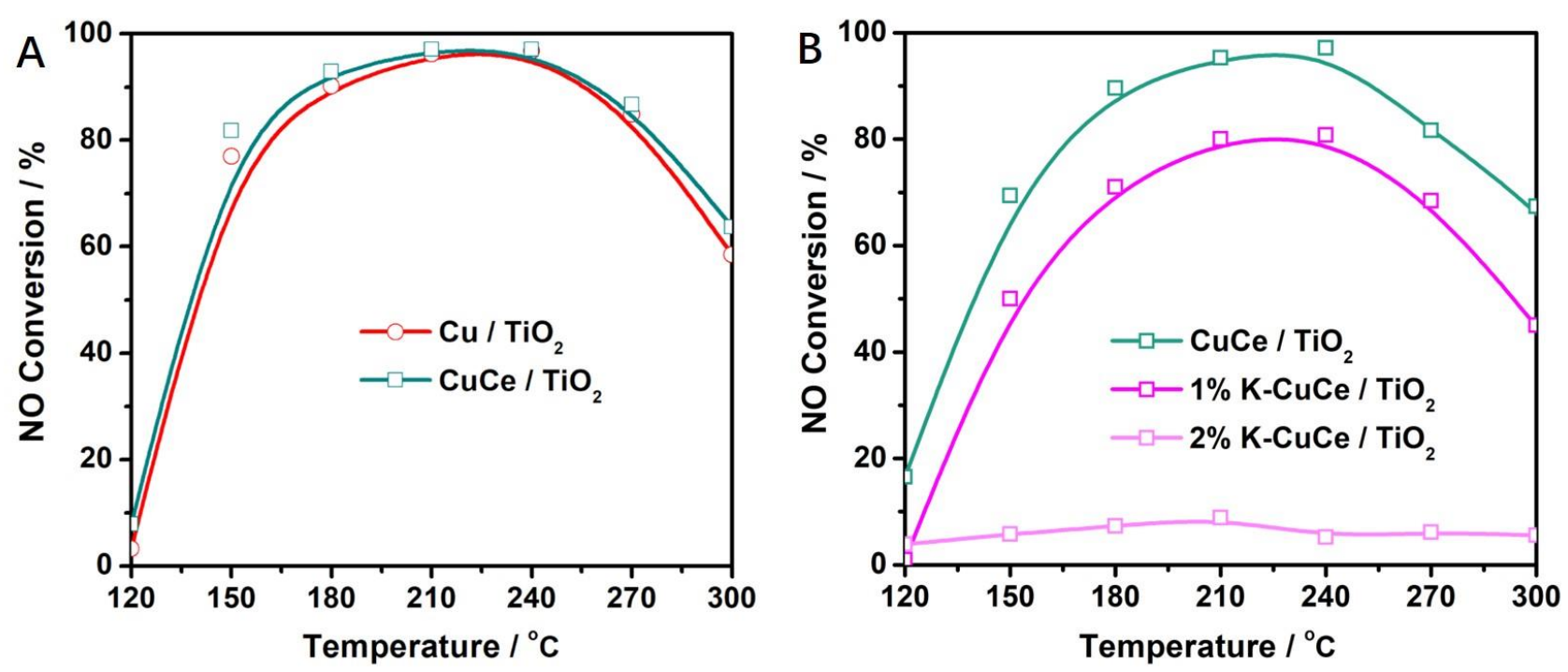

Figure S6. Plots of $\mathrm{NO}$ conversion as a function of reaction temperature for $(\mathrm{A}) \mathrm{Cu} / \mathrm{TiO}_{2}, \mathrm{CuCe} / \mathrm{TiO}_{2}$ catalysts and (B) $\mathrm{CuCe} / \mathrm{TiO}_{2}$ catalyst in the presence of $1 \mathrm{wt} \%$ and $2 \mathrm{wt} \% \mathrm{~K}$. Reaction conditions: 500 ppm NO, $500 \mathrm{ppm} \mathrm{NH}_{3}, 5 \mathrm{vol} \% \mathrm{O}_{2}, \mathrm{~N}_{2}$ as the balance gas, GHSV of $30000 \mathrm{~h}^{-1}$. 


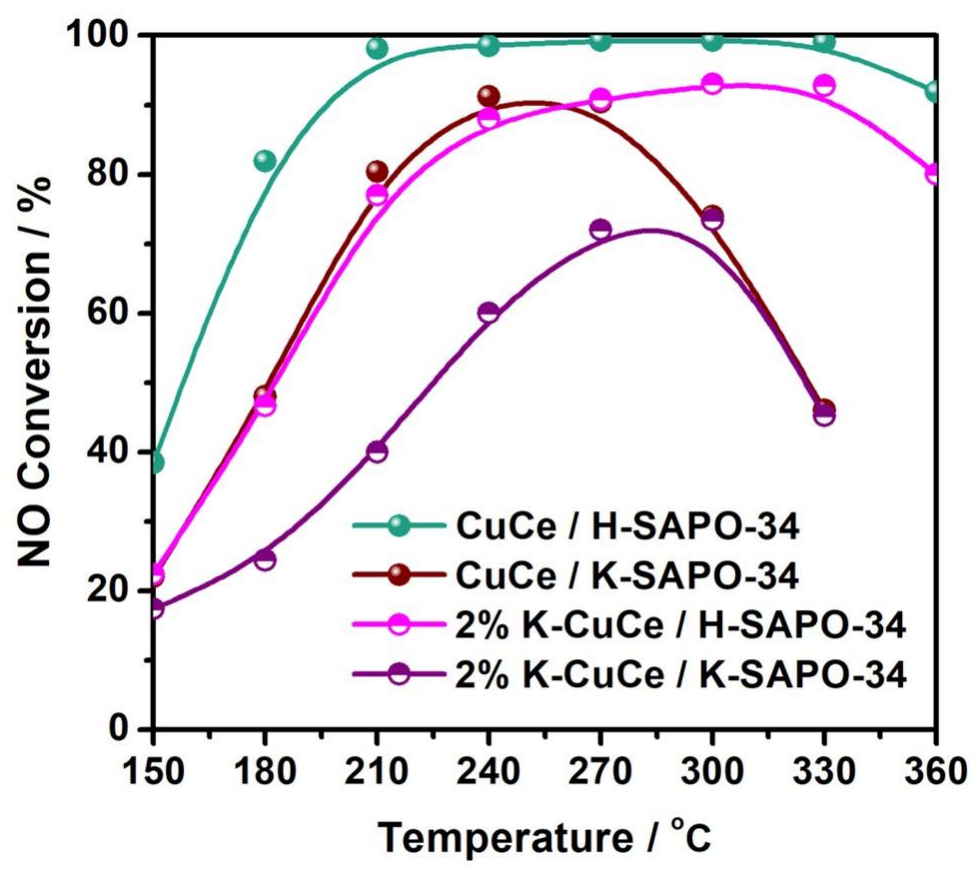

Figure S7. Plots of NO conversion as a function of reaction temperature for $\mathrm{CuCe} / \mathrm{H}-\mathrm{SAPO}-34$ and $\mathrm{CuCe} / \mathrm{K}-\mathrm{SAPO}-34$ catalysts in the presence of $2 \mathrm{wt} \% \mathrm{~K}$. Reaction conditions: $500 \mathrm{ppm}$ NO, $500 \mathrm{ppm}$ $\mathrm{NH}_{3}, 5 \mathrm{vol} \% \mathrm{O}_{2}, \mathrm{~N}_{2}$ as the balance gas, GHSV of $30000 \mathrm{~h}^{-1}$. 

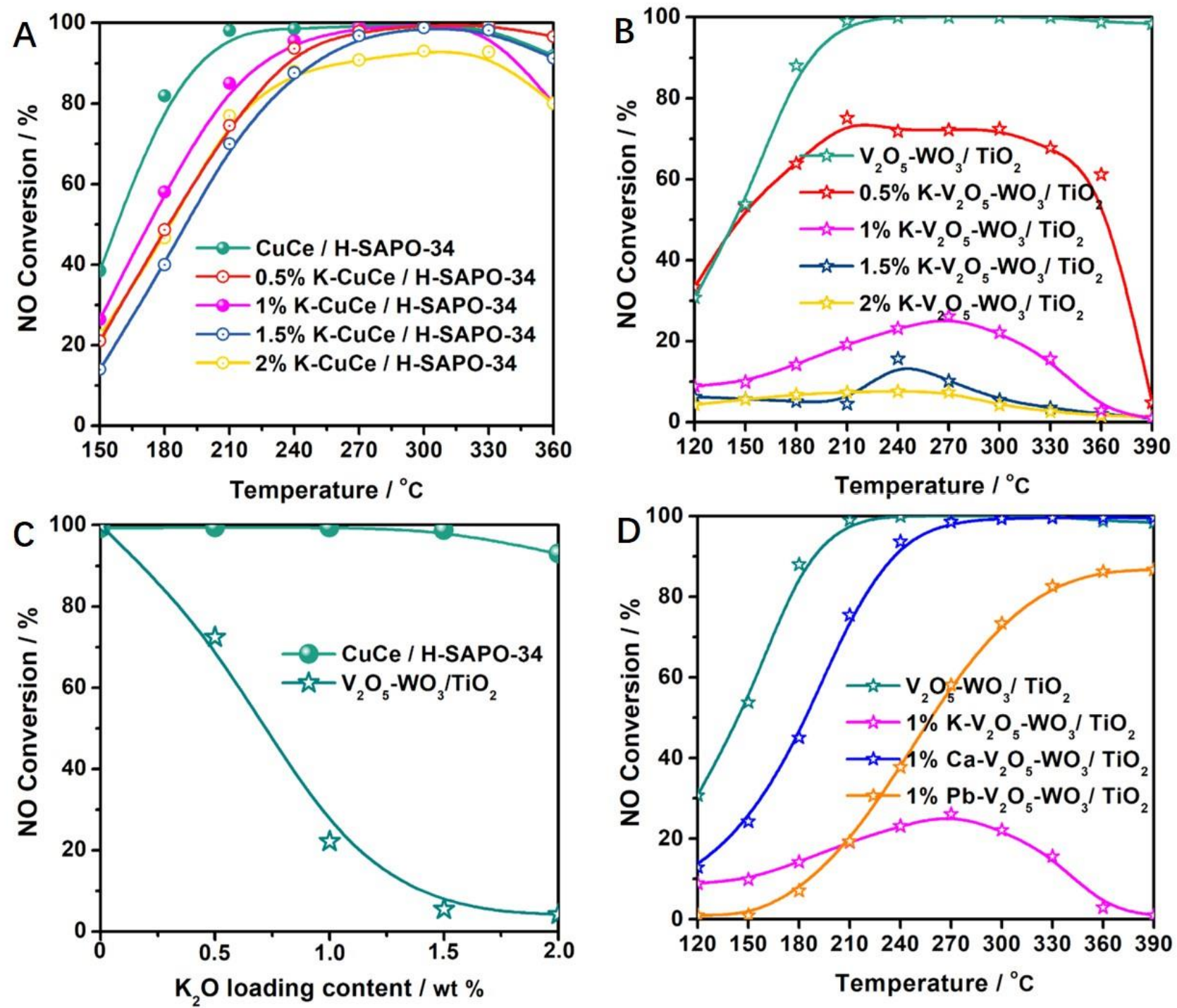

Figure S8. Plots of NO conversion as a function of reaction temperature for (A) CuCe/H-SAPO-34 catalyst and (B) $\mathrm{V}_{2} \mathrm{O}_{5}-\mathrm{WO}_{3} / \mathrm{TiO}_{2}$ commercial catalyst in the presence of $0.5 \mathrm{wt} \%, 1 \mathrm{wt} \%, 1.5 \mathrm{wt} \%, 2$ wt $\%$ K. (C) The differential NO conversion at $300{ }^{\circ} \mathrm{C}$ for $\mathrm{CuCe} / \mathrm{H}-\mathrm{SAPO}-34$ and $\mathrm{V}_{2} \mathrm{O}_{5}-\mathrm{WO}_{3} / \mathrm{TiO}_{2}$ catalysts in the presence of various amount of alkali metal. (D) Plots of NO conversion as a function of reaction temperature for $\mathrm{V}_{2} \mathrm{O}_{5}-\mathrm{WO}_{3} / \mathrm{TiO}_{2}$ commercial catalyst in the presence of $1 \mathrm{wt} \% \mathrm{~K}, \mathrm{Ca}$, or $\mathrm{Pb}$. Reaction conditions: $500 \mathrm{ppm} \mathrm{NO}, 500 \mathrm{ppm} \mathrm{NH}_{3}, 5 \mathrm{vol} \% \mathrm{O}_{2}, \mathrm{~N}_{2}$ as the balance gas, GHSV of 30 $000 \mathrm{~h}^{-1}$

Note: $\mathrm{CuCe} / \mathrm{H}-\mathrm{SAPO}-34$ had no obvious decline with $\mathrm{K}$ addition while the $\mathrm{V}_{2} \mathrm{O}_{5}-\mathrm{WO}_{3} / \mathrm{TiO}_{2}$ was obviously deactivated after alkali metal poisoning (Figure S8A). As the amount of added alkali metal 
increased, the deNO $\mathrm{N}_{\mathrm{x}}$ performance of $\mathrm{V}_{2} \mathrm{O}_{5}-\mathrm{WO}_{3} / \mathrm{TiO}_{2}$ gradually decreased and completely deactivated with $2 \mathrm{wt} \% \mathrm{~K}$ added (Figure S8B). When directly compared the differential NO conversion at $300{ }^{\circ} \mathrm{C}$ for $\mathrm{CuCe} / \mathrm{H}-\mathrm{SAPO}-34$ and $\mathrm{V}_{2} \mathrm{O}_{5}-\mathrm{WO}_{3} / \mathrm{TiO}_{2}$ in the presence of various amount of alkali metal, the activity of CuCe/H-SAPO-34 was nearly unchanged when the amount of $\mathrm{K}$ increased to $2 \mathrm{wt} \%$ (Figure $\mathrm{S} 8 \mathrm{C})$. Besides, $\mathrm{Ca}$ and $\mathrm{Pb}$ resistance of $\mathrm{V}_{2} \mathrm{O}_{5}-\mathrm{WO}_{3} / \mathrm{TiO}_{2}$ catalyst was also studied and they were quite lower than that of CuCe/H-SAPO-34 (Figure S8D). These results further demonstrated that the $\mathrm{CuCe} / \mathrm{H}-\mathrm{SAPO}-34$ catalyst had great prospects for the purification of $\mathrm{NO}_{\mathrm{x}}$ in practical application. 


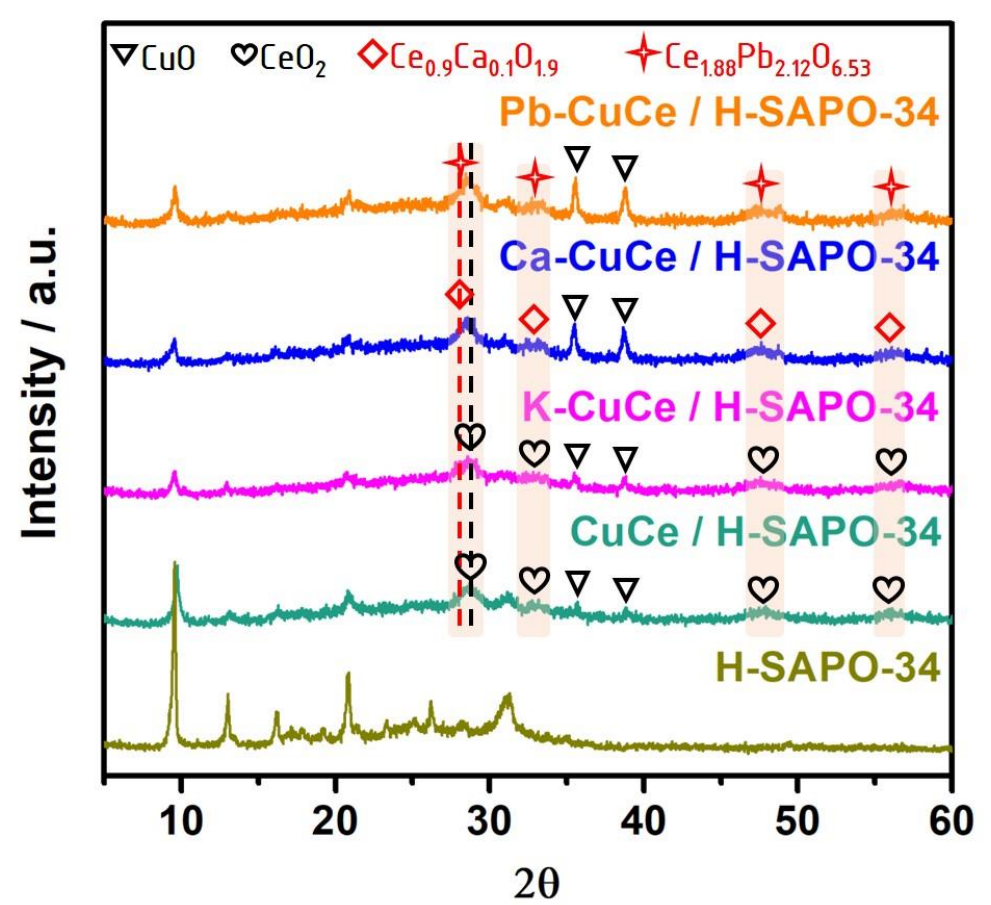

Figure S9. XRD patterns of CuCe/H-SAPO-34 and poisoned catalysts.

Note: The typical characteristic peaks of commercial H-SAPO-34 were in-line with the structure of SAPO-34 (PDF no. 47-0429). When the active components were loaded, obvious diffraction peaks due to $\mathrm{CuO}$ (PDF no. 45-0937) and $\mathrm{CeO}_{2}$ (PDF no. 34-0394) were observed in the diffraction pattern of the $\mathrm{CuCe} / \mathrm{H}-\mathrm{SAPO}-34$ catalyst (Figure S9). 

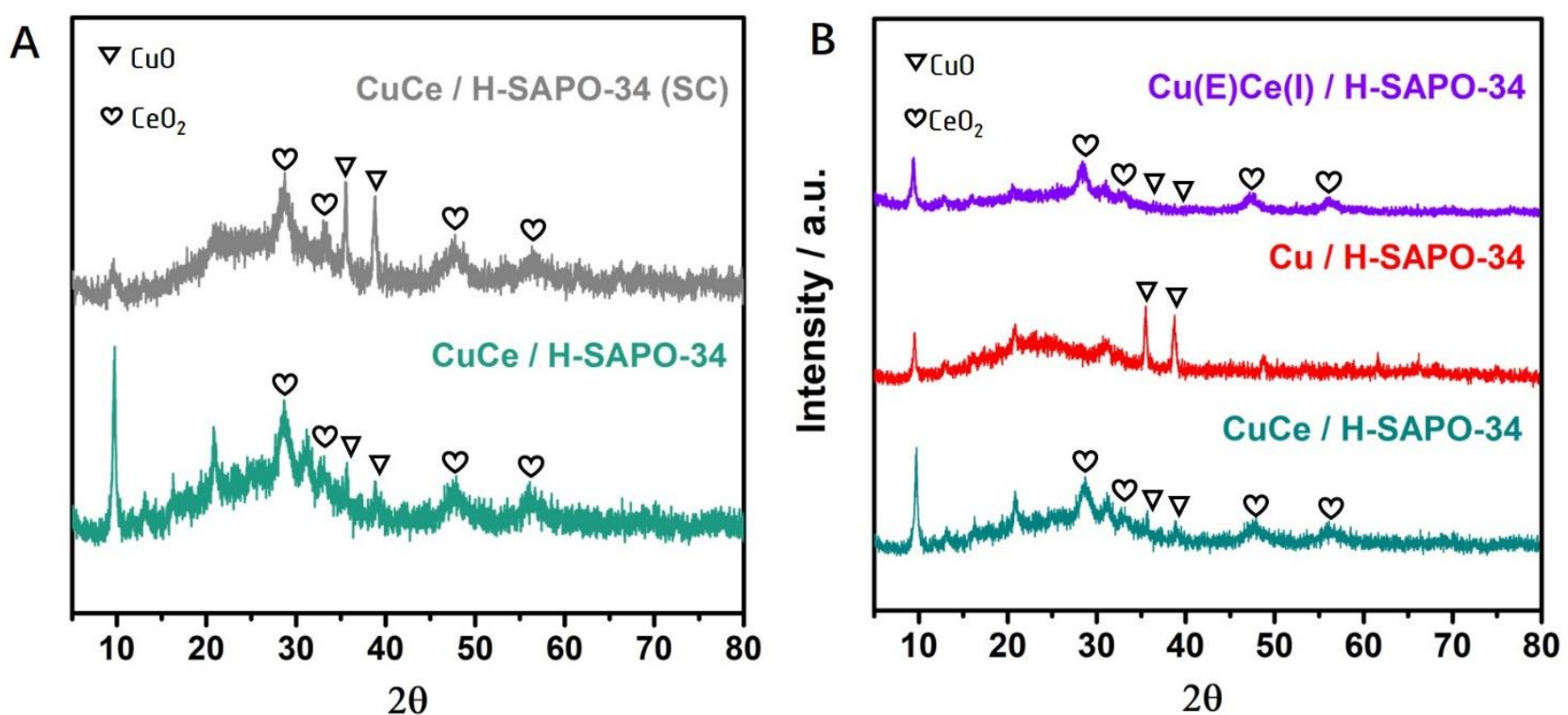

Figure S10. XRD patterns of (A) CuCe/H-SAPO-34 catalyst before and after the second calcination and (B) $\mathrm{CuCe} / \mathrm{H}-\mathrm{SAPO}-34, \mathrm{Cu} / \mathrm{H}-\mathrm{SAPO}-34, \mathrm{Cu}(\mathrm{E}) \mathrm{Ce}(\mathrm{I}) / \mathrm{H}-\mathrm{SAPO}-34$ catalysts. 

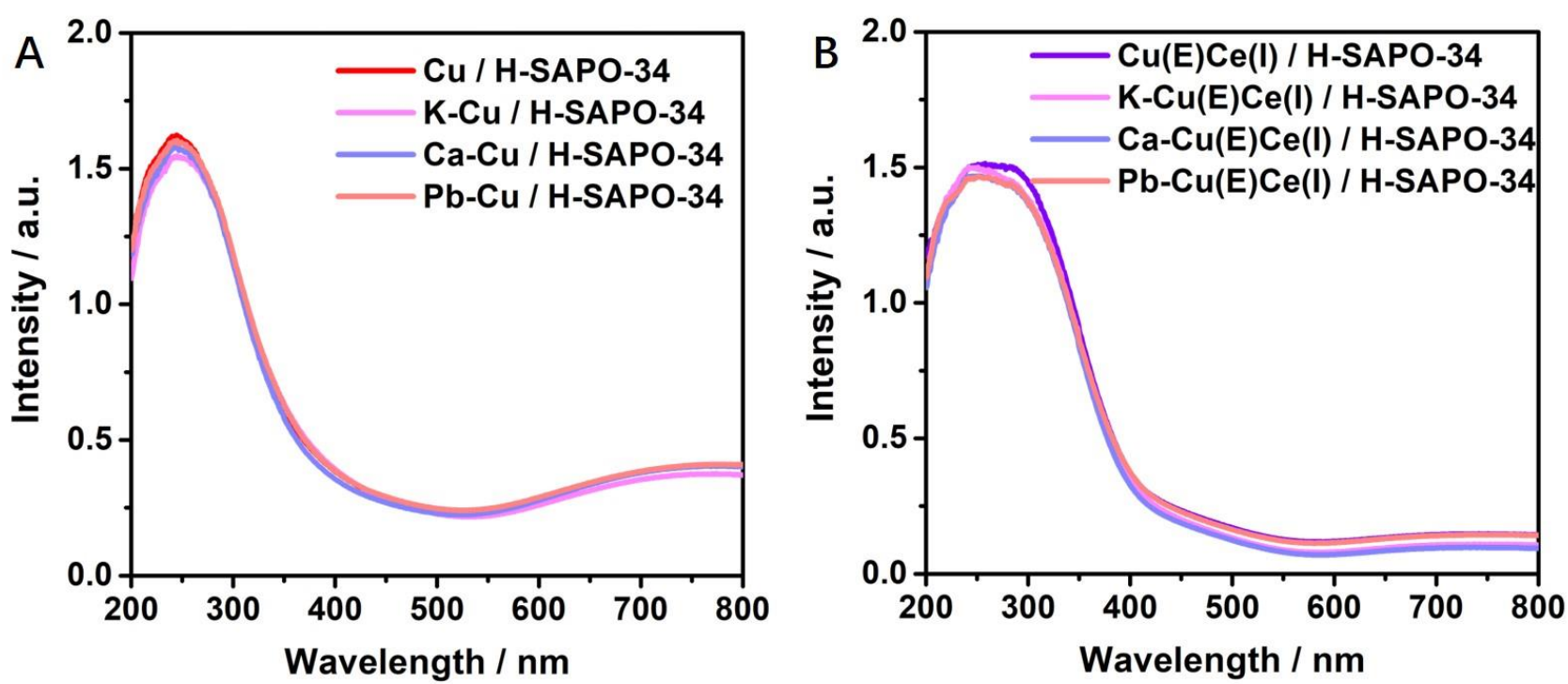

Figure S11. UV-Vis-NIR DRS spectra of (A) Cu/H-SAPO-34 and (B) $\mathrm{Cu}(\mathrm{E}) \mathrm{Ce}(\mathrm{I}) / \mathrm{H}-\mathrm{SAPO}-34$ catalysts in the presence of $1 \mathrm{wt} \% \mathrm{~K}, \mathrm{Ca}$, or $\mathrm{Pb}$. 

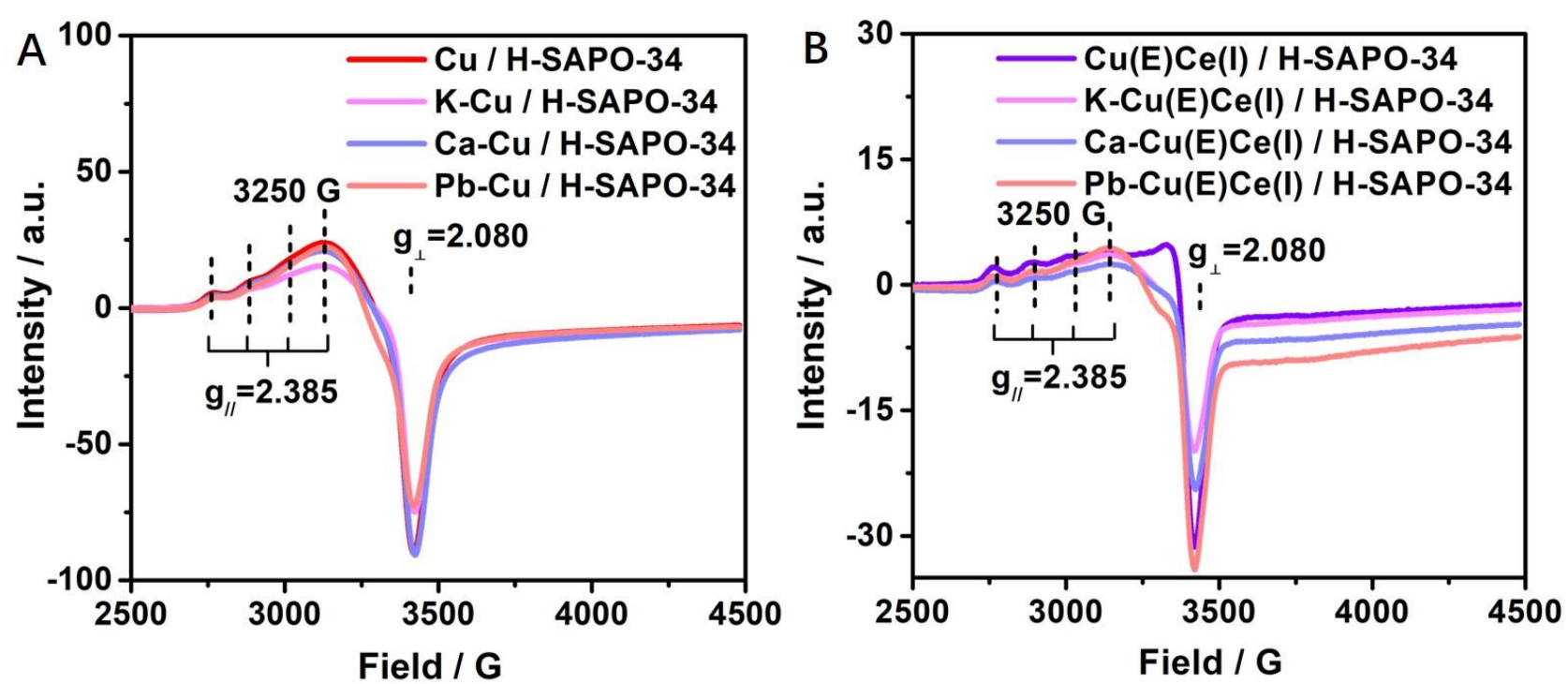

Figure S12. EPR spectra measured at $273 \mathrm{~K}$ of (A) Cu/H-SAPO-34 and (B) $\mathrm{Cu}(\mathrm{E}) \mathrm{Ce}(\mathrm{I}) / \mathrm{H}-\mathrm{SAPO}-34$ catalysts in the presence of $1 \mathrm{wt} \% \mathrm{~K}, \mathrm{Ca}$, or $\mathrm{Pb}$. 

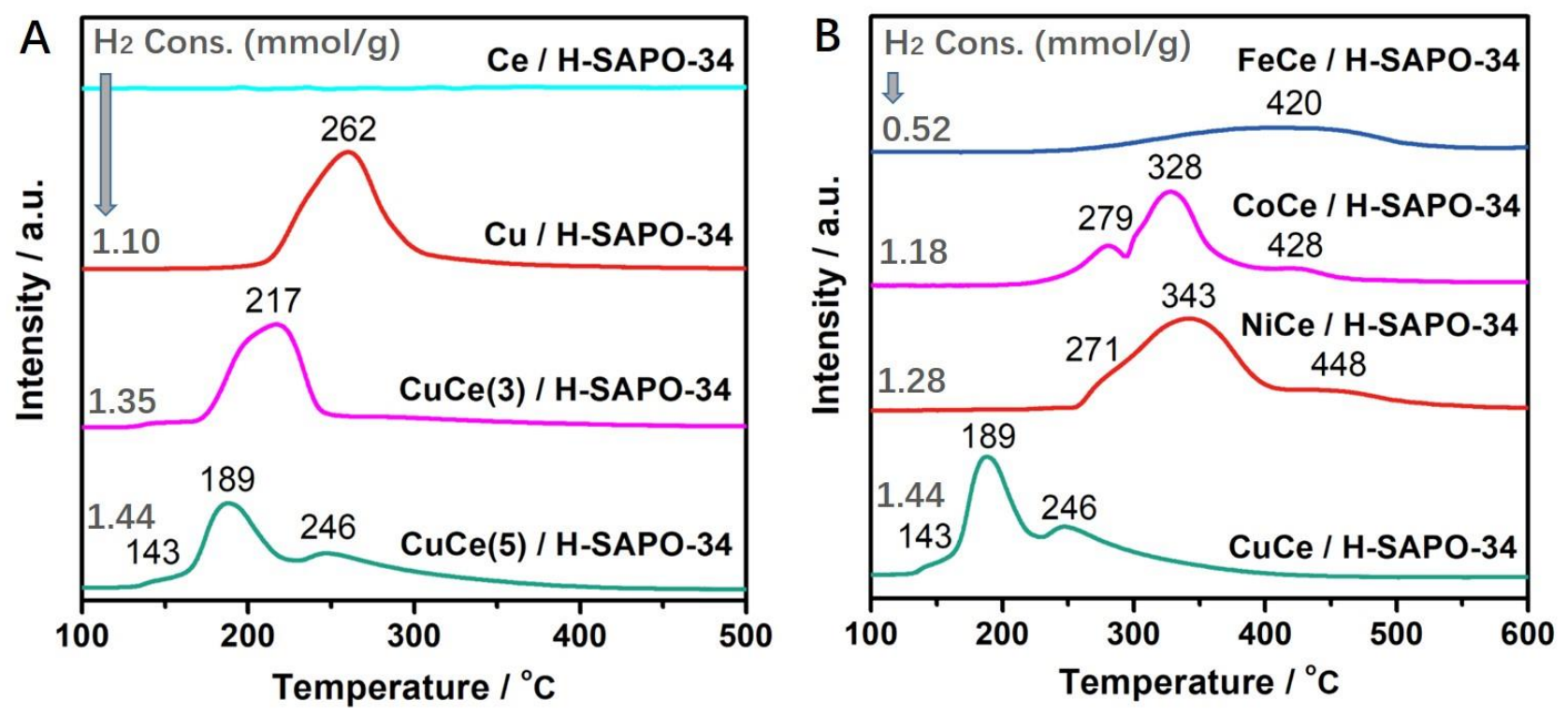

Figure S13. $\mathrm{H}_{2}$-TPR profiles and $\mathrm{H}_{2}$ consumption amount of (A) Ce/H-SAPO-34, Cu/H-SAPO-34, $\mathrm{CuCe}(3) / \mathrm{H}-\mathrm{SAPO}-34, \mathrm{CuCe}(5) / \mathrm{H}-\mathrm{SAPO}-34$ catalysts and (B) FeCe/H-SAPO-34, CoCe/H-SAPO-34, $\mathrm{NiCe} / \mathrm{H}-\mathrm{SAPO}-34, \mathrm{CuCe} / \mathrm{H}-\mathrm{SAPO}-34$ catalysts.

Note: For $\mathrm{Cu} / \mathrm{H}-\mathrm{SAPO}-34$, the peak at $262{ }^{\circ} \mathrm{C}$ came from the reduction of isolated $\mathrm{Cu}^{2+}$ ions in cationic positions ${ }^{1}$. With the gradual addition of Ce additives, the reduction peak shifted to $217{ }^{\circ} \mathrm{C}$ in $\mathrm{CuCe}(3) / \mathrm{H}-\mathrm{SAPO}-34$ and split into three overlapped peaks at $143{ }^{\circ} \mathrm{C}, 189{ }^{\circ} \mathrm{C}$ and $246{ }^{\circ} \mathrm{C}$ accompanied with higher $\mathrm{H}_{2}$ consumption amount that originated from Ce species reduction. As the Ce species had no obvious reduction, this shifting might be due to the stronger interaction of $\mathrm{Cu}^{2+}$ and $\mathrm{H}-\mathrm{SAPO}-34$ after adding $\mathrm{Ce}$ that resulted in the $\mathrm{Cu}$ species could be reduced much easier ${ }^{2}$. It could also be explained that the introduction of $\mathrm{Ce}$ promoted the generation of a redox cycle $\left(\mathrm{Cu}^{2+}+\mathrm{Ce}^{3+} \leftrightarrow \mathrm{Cu}^{+}+\right.$ $\mathrm{Ce}^{4+}$ ) and improved the reduction ability of the catalyst, which explained the improvement in the lowtemperature activity ${ }^{1}$. Besides, the $\mathrm{CuCe} / \mathrm{H}-\mathrm{SAPO}-34$ catalyst which achieved optimal SCR activity also exhibited much easier reduced active species and more $\mathrm{H}_{2}$ consumption amount when compared with the FeCe/H-SAPO-34, CoCe/H-SAPO-34, and NiCe/H-SAPO-34 catalysts. 

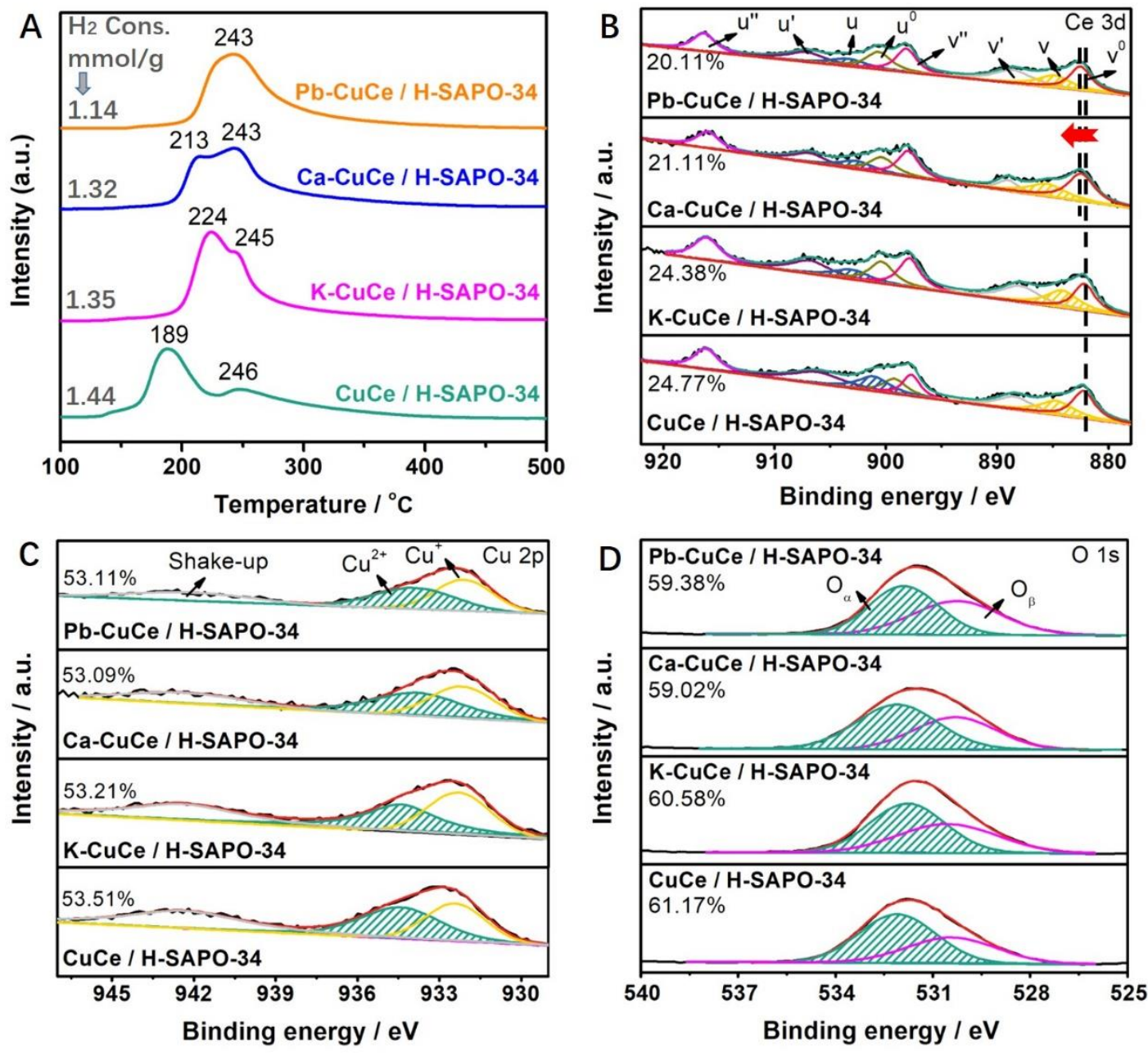

Figure S14. (A) $\mathrm{H}_{2}$-TPR curves and XPS spectra for (B) $\mathrm{Ce} 3 \mathrm{~d},(\mathrm{C}) \mathrm{Cu} 2 \mathrm{p}$ and (D) $\mathrm{O} 1 \mathrm{~s}$ of $\mathrm{CuCe} / \mathrm{H}-$ SAPO-34 and poisoned catalysts.

Note: After the addition of $\mathrm{K}$ and $\mathrm{Ca}$, the reduction peaks of $\mathrm{K}-\mathrm{CuCe} / \mathrm{H}-\mathrm{SAPO}-34$ and $\mathrm{Ca}-\mathrm{CuCe} / \mathrm{H}-$ SAPO-34 catalysts shifted slightly towards the high-temperature range, indicating that the added metals interacted strongly with the H-SAPO-34 support ${ }^{3}$. In the $\mathrm{Pb}-\mathrm{CuCe} / \mathrm{H}-\mathrm{SAPO}-34$, the reduction peak centered at $243{ }^{\circ} \mathrm{C}$ was attributed to the overlap of $\mathrm{Cu}^{2+} \rightarrow \mathrm{Cu}^{+}$and $\mathrm{Cu}^{+} \rightarrow \mathrm{Cu}^{0}$ reduction peaks, which was significantly different from the other three catalysts. The reduction peaks of $\mathrm{Pb}-\mathrm{CuCe} / \mathrm{H}-$ SAPO-34 were similar to those with lower Ce content $(<5 \mathrm{wt} \%)$, indicating that $\mathrm{Pb}$ preferred to combine with Ce species and prevented poisoning of the active copper species. The $\mathrm{H}_{2}$ consumption also showed the combination of $\mathrm{Pb}$ and $\mathrm{Ce}$ reduced $\mathrm{H}_{2}$ consumption and redox ability (Figure $\mathrm{S} 14 \mathrm{~A}$ ). 
In the Ce 3d spectrum (Figure S14B), catalysts were fitted into eight characteristic peaks by Gaussian-Lorentz fitting and attributed to the Ce $3 \mathrm{~d}_{5 / 2}$ and Ce $3 \mathrm{~d}_{3 / 2}$ spin-orbit components. The peaks labeled v0 (882.1 eV), v' (887.2 eV), v" (897.8 eV), u (901.1 eV), u' (907.2 eV), and u" (916.2 eV) corresponded to $\mathrm{Ce}^{4+}$, while the peaks labeled as $\mathrm{v}(884.6 \mathrm{eV})$ and $\mathrm{u}(904.2 \mathrm{eV})$ belonged to the $\mathrm{Ce}^{3+}$ species ${ }^{4}$. It was apparent that the Ce valence states on the surface of the Ce-containing catalysts was a co-existing mixture of $\mathrm{Ce}^{4+}$ and $\mathrm{Ce}^{3+}$. Meanwhile, electron transfer between $\mathrm{Ce}^{3+}$ and $\mathrm{Ce}^{4+}$ produced oxygen vacancies ${ }^{5}$, so higher $\mathrm{Ce}^{3+}$ content would likely enrich the redox cycle and facilitate the SCR reaction $^{2}$.

The $\mathrm{Cu} 2 \mathrm{p}$ spectrum showed a main $\mathrm{Cu} 2 \mathrm{p}_{3 / 2}$ peak at $934.4 \mathrm{eV}$ and a shake-up peak centered near 942.0 eV, which was attributed to $\mathrm{Cu}^{2+}$ species (Figure 3C). Moreover, another peak detected near 932.4 $\mathrm{eV}$ revealed the presence of $\mathrm{Cu}^{+}$species ${ }^{6}$. Generally, the redox property of the $\mathrm{Cu}^{2+}$ phase was stronger than $\mathrm{Cu}$ species in lower valence states, and their favorable redox cycle improved the deNO $\mathrm{x}_{\mathrm{x}}$ performance.

The $\mathrm{O} 1 \mathrm{~s}$ bands were divided into two characteristic peaks (Figure S14D). The peak located near $530.4 \mathrm{eV}$ belonged to the lattice oxygen (denoted as $\mathrm{O}_{\beta}$ ) such as $\mathrm{O}_{2}{ }^{-}$, and the peak located near 531.7 eV was assigned to surface-adsorbed oxygen (denoted as $\mathrm{O}_{\alpha}$ ) such as $\mathrm{O}^{-}$and $\mathrm{O}_{2}{ }^{2-}{ }^{4}$. Generally, $\mathrm{O}_{\alpha}$ was more active than $\mathrm{O}_{\beta}$ in the SCR reaction due to its higher mobility and reactivity. 

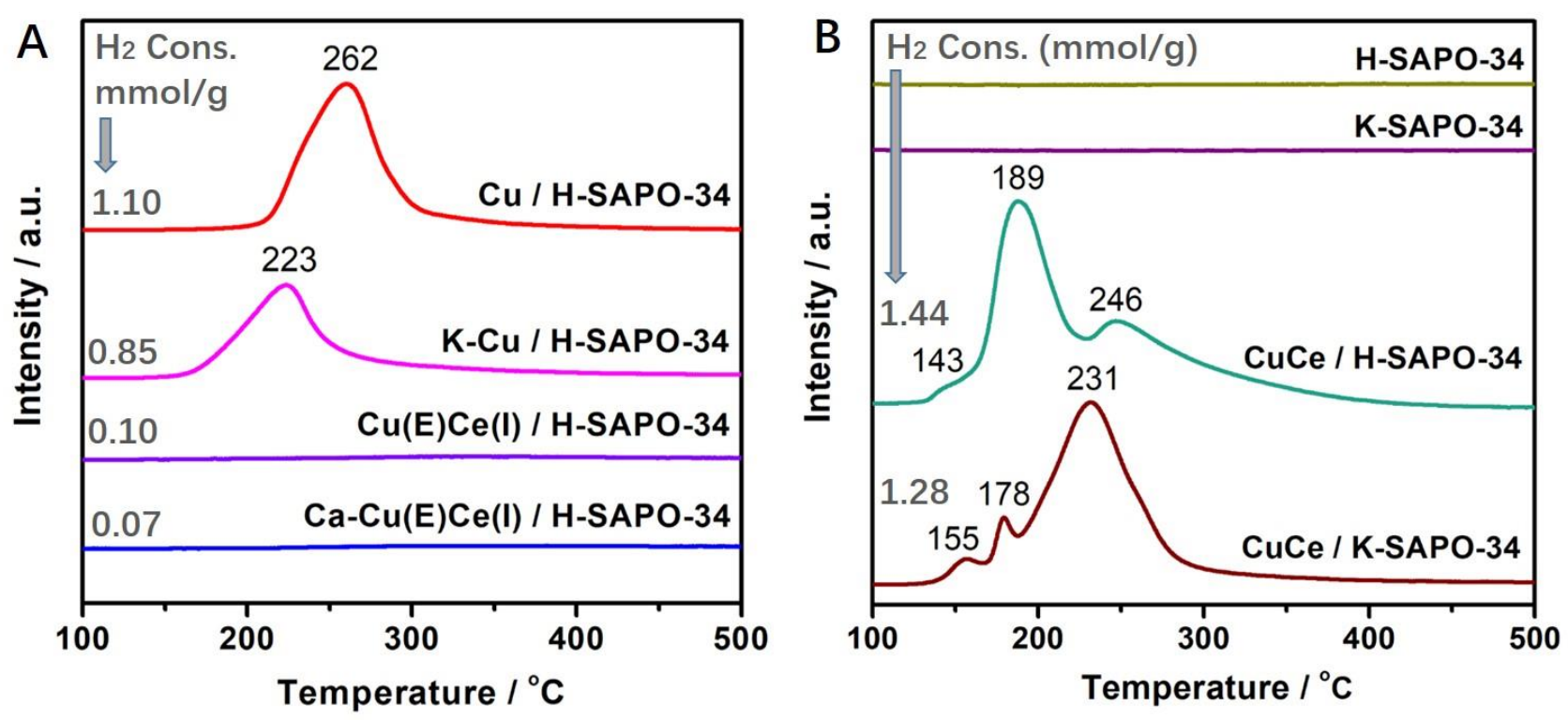

Figure $\mathrm{S15} . \mathrm{H}_{2}$-TPR profiles and $\mathrm{H}_{2}$ consumption amount of (A) $\mathrm{Cu} / \mathrm{H}-\mathrm{SAPO}-34, \mathrm{~K}-\mathrm{Cu} / \mathrm{H}-\mathrm{SAPO}-34$, $\mathrm{Cu}(\mathrm{E}) \mathrm{Ce}(\mathrm{I}) / \mathrm{H}-\mathrm{SAPO}-34, \mathrm{Ca}-\mathrm{Cu}(\mathrm{E}) \mathrm{Ce}(\mathrm{I}) / \mathrm{H}-\mathrm{SAPO}-34$ catalysts and (B) H-SAPO-34, K-SAPO-34, $\mathrm{CuCe} / \mathrm{H}-\mathrm{SAPO}-34, \mathrm{CuCe} / \mathrm{K}-\mathrm{SAPO}-34$ catalysts.

Note: $\mathrm{The} \mathrm{Cu}(\mathrm{E}) \mathrm{Ce}(\mathrm{I}) / \mathrm{H}-\mathrm{SAPO}-34$ showed no obvious reduction peak, which might be mainly caused by the spillover of active $\mathrm{Cu}$ species and decline of redox ability that also confirmed by UV-Vis-NIR results. After poisoning, the $\mathrm{K}-\mathrm{Cu} / \mathrm{H}-\mathrm{SAPO}-34$ and $\mathrm{Ca}-\mathrm{Cu}(\mathrm{E}) \mathrm{Ce}(\mathrm{I}) / \mathrm{H}-\mathrm{SAPO}-34$ that encountered SCR activity decrease also revealed decline of $\mathrm{H}_{2}$ consumption (Figure $\mathrm{S} 15 \mathrm{~A}$ ). The raw H-SAPO-34 and $\mathrm{K}$ exchanged K-SAPO-34 both had no reduced species in the region of $100-500{ }^{\circ} \mathrm{C}$, further proving that the redox ability was resulted from the active metal components. Compared with $\mathrm{CuCe} / \mathrm{H}-\mathrm{SAPO}-34$, the reduction peaks of CuCe/K-SAPO-34 all shifted to higher temperature side and the $\mathrm{H}_{2}$ consumption decreased, further indicating the strong interaction of $\mathrm{K}$ with H-SAPO-34 support and resulting in descend of activity (Figure S15B). 

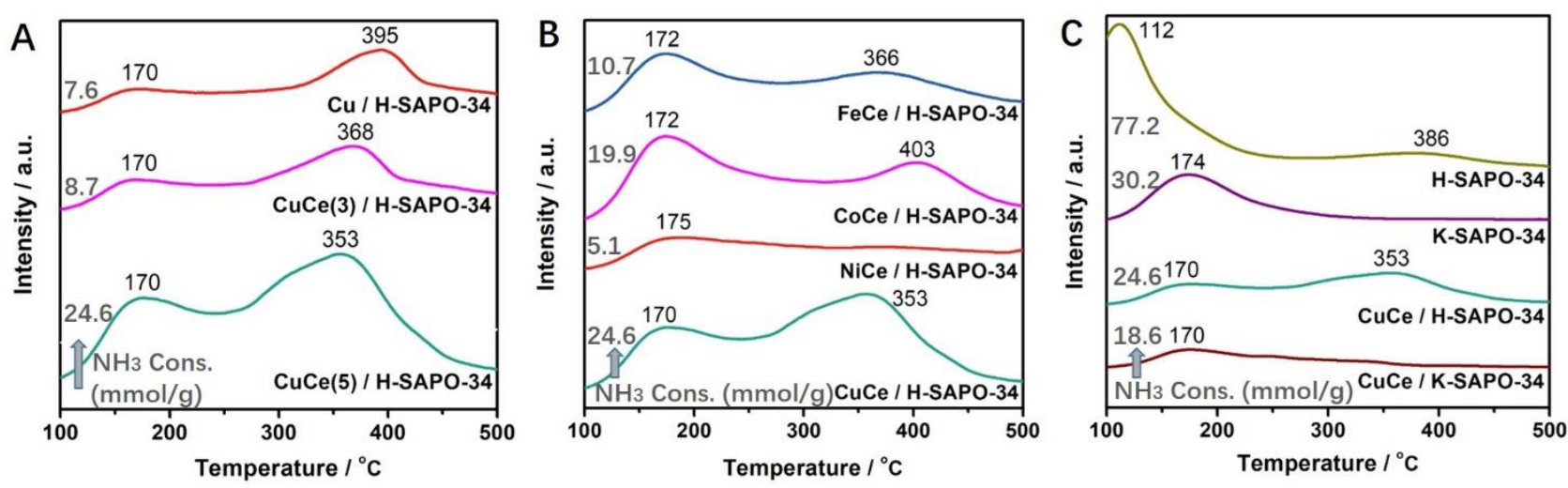

Figure S16. $\mathrm{NH}_{3}$-TPD profiles of (A) $\mathrm{Cu} / \mathrm{H}-\mathrm{SAPO}-34, \mathrm{CuCe}(3) / \mathrm{H}-\mathrm{SAPO}-34, \mathrm{CuCe}(5) / \mathrm{H}-\mathrm{SAPO}-34$ catalysts and (B) FeCe/H-SAPO-34, CoCe/H-SAPO-34, NiCe/H-SAPO-34, CuCe/H-SAPO-34 catalysts and (C) H-SAPO-34, K-SAPO-34, CuCe/H-SAPO-34, CuCe/K-SAPO-34 catalysts.

Note: It was observed that the latter one gradually migrated to the low-temperature region and the total $\mathrm{NH}_{3}$ desorption amount increased as the Ce content increased (Figure S16A). This might be caused that the addition of Ce provided a part of Lewis acid sites on one hand, and also enhanced the interaction effect with $\mathrm{Cu}$ sites to form more unstable surface Lewis acid sites on the other hand ${ }^{7}$. The $\mathrm{CuCe} / \mathrm{H}-\mathrm{SAPO}-34$ was also confirmed to own the most weak and medium-strong acid sites when compared with FeCe/H-SAPO-34, CoCe/H-SAPO-34, NiCe/H-SAPO-34 catalysts (Figure S16B). 


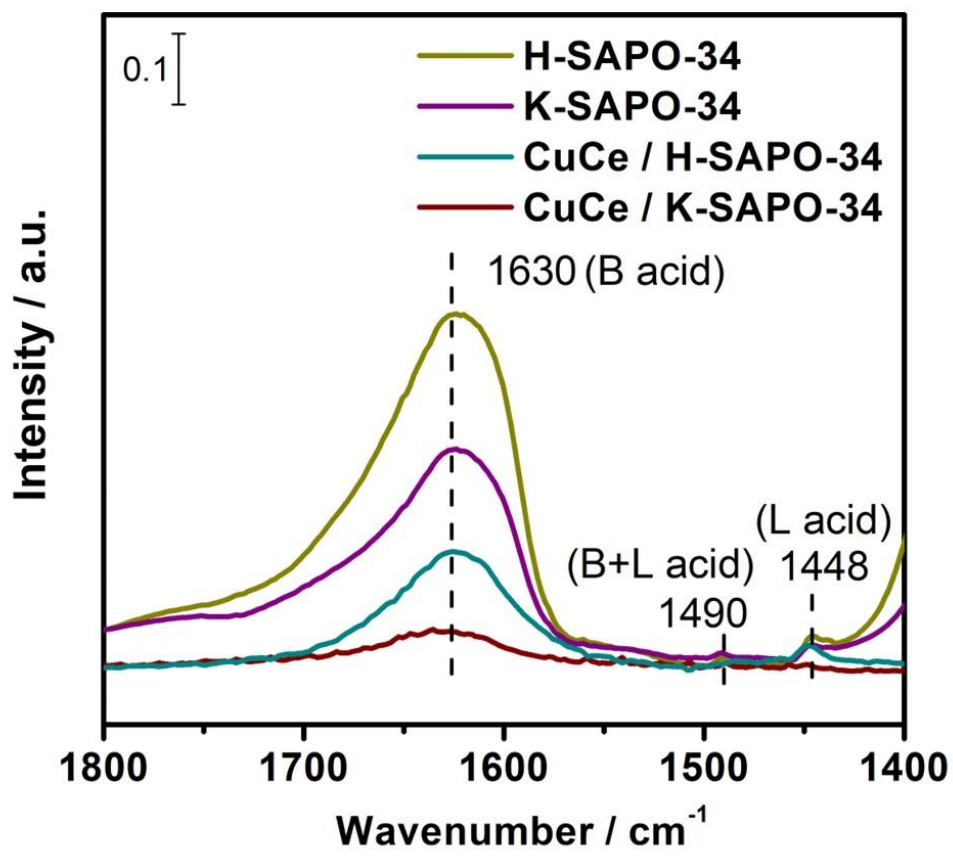

Figure S17. Py-IR spectra for H-SAPO-34, K-SAPO-34, CuCe/H-SAPO-34, CuCe/K-SAPO-34 catalysts. 

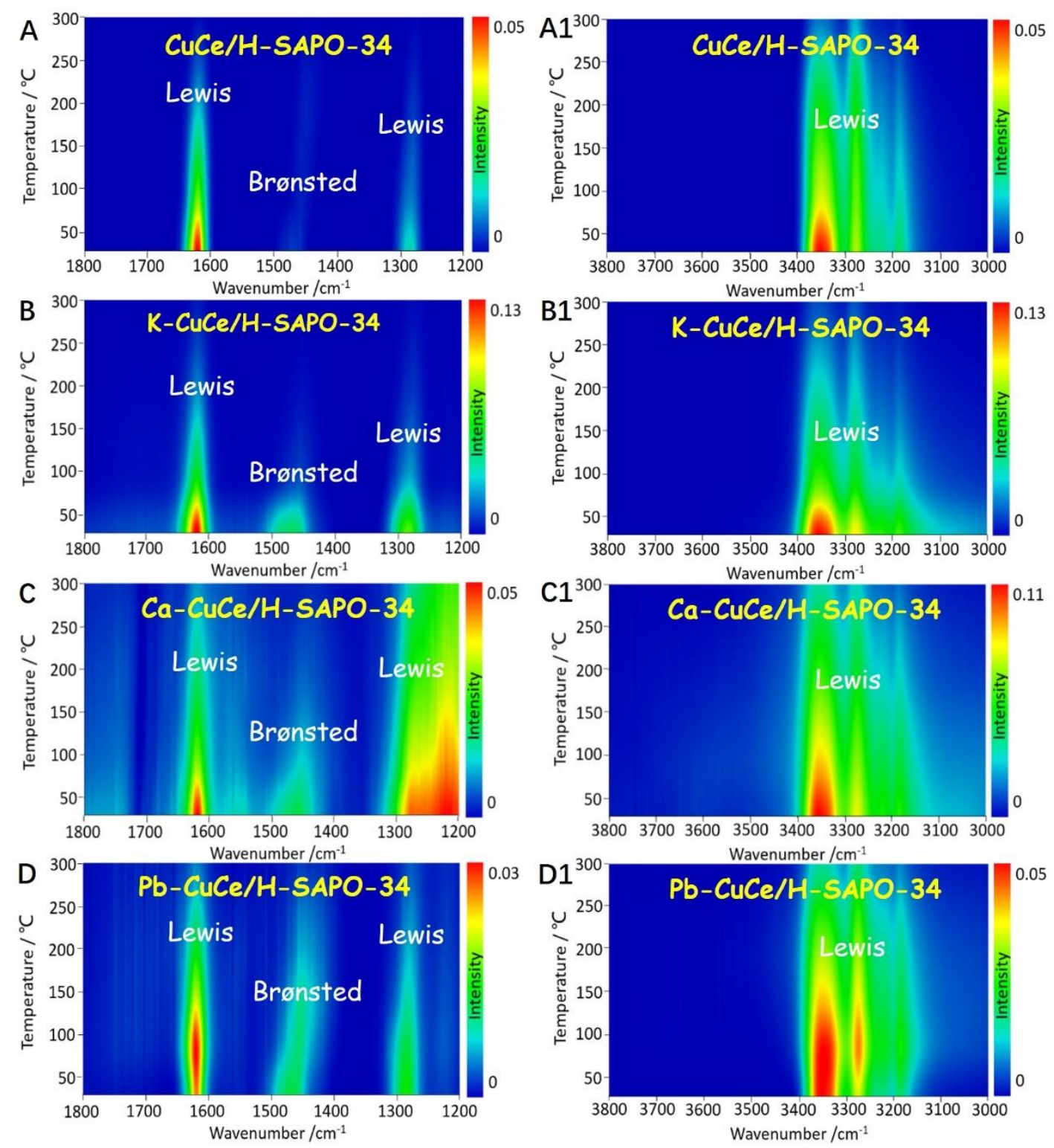

Figure S18. The corresponding mapping results of in situ DRIFTs spectra of $\mathrm{NH}_{3}$ desorption in the range of $1200-1800 \mathrm{~cm}^{-1}$ and $3000-3800 \mathrm{~cm}^{-1}$ over (A) and (A1) CuCe/H-SAPO-34, (B) and (B1) K$\mathrm{CuCe} / \mathrm{H}-\mathrm{SAPO}-34,(\mathrm{C})$ and (C1) Ca-CuCe/H-SAPO-34, (D) and (D1) Pb-CuCe/H-SAPO-34 catalysts as a function of temperature after exposure to a flow of $500 \mathrm{ppm} \mathrm{NH}_{3}$ for $1 \mathrm{~h}$ at $30{ }^{\circ} \mathrm{C}$. 

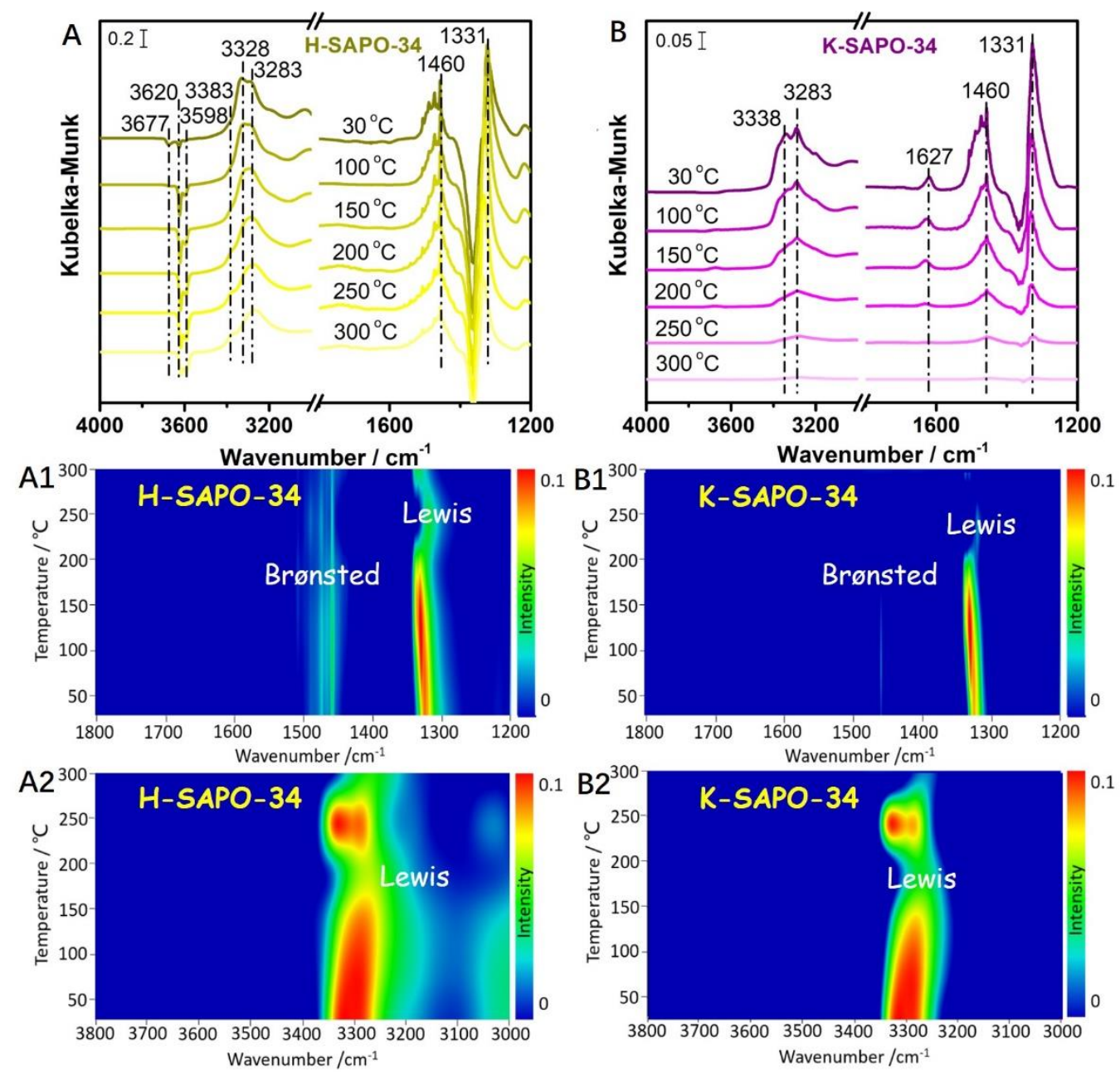

Figure S19. In situ DRIFTs spectra of $\mathrm{NH}_{3}$ desorption over (A) H-SAPO-34 and (B) K-SAPO-34 supports as a function of temperature after exposure to a flow of $500 \mathrm{ppm} \mathrm{NH}_{3}$ for $1 \mathrm{~h}$ at $30{ }^{\circ} \mathrm{C}$ and the corresponding mapping results in the range of $1200-1800 \mathrm{~cm}^{-1}$ and $3000-3800 \mathrm{~cm}^{-1}$ over (A1) and (A2) H-SAPO-34, (B1) and (B2) K-SAPO-34 supports.

Note: To further prove H-SAPO-34 could capture alkaline metals, in situ DRIFTs of $\mathrm{NH}_{3}$ desorption over H-SAPO-34 and K-SAPO-34 were carried out (Figure S19). After K ${ }^{+}$exchanged, hydroxyl peaks in the range of $3598-3677 \mathrm{~cm}^{-1}$ all disappeared and peak strength greatly reduced, indicating $\mathrm{K}^{+}$could be effectively trapped by H-SAPO-34. Meanwhile, it was easy to conclude that a part of replacement of protons in H-SAPO-34 by K ions induced great loss of acidity in both Lewis and Brønsted acid sites. 

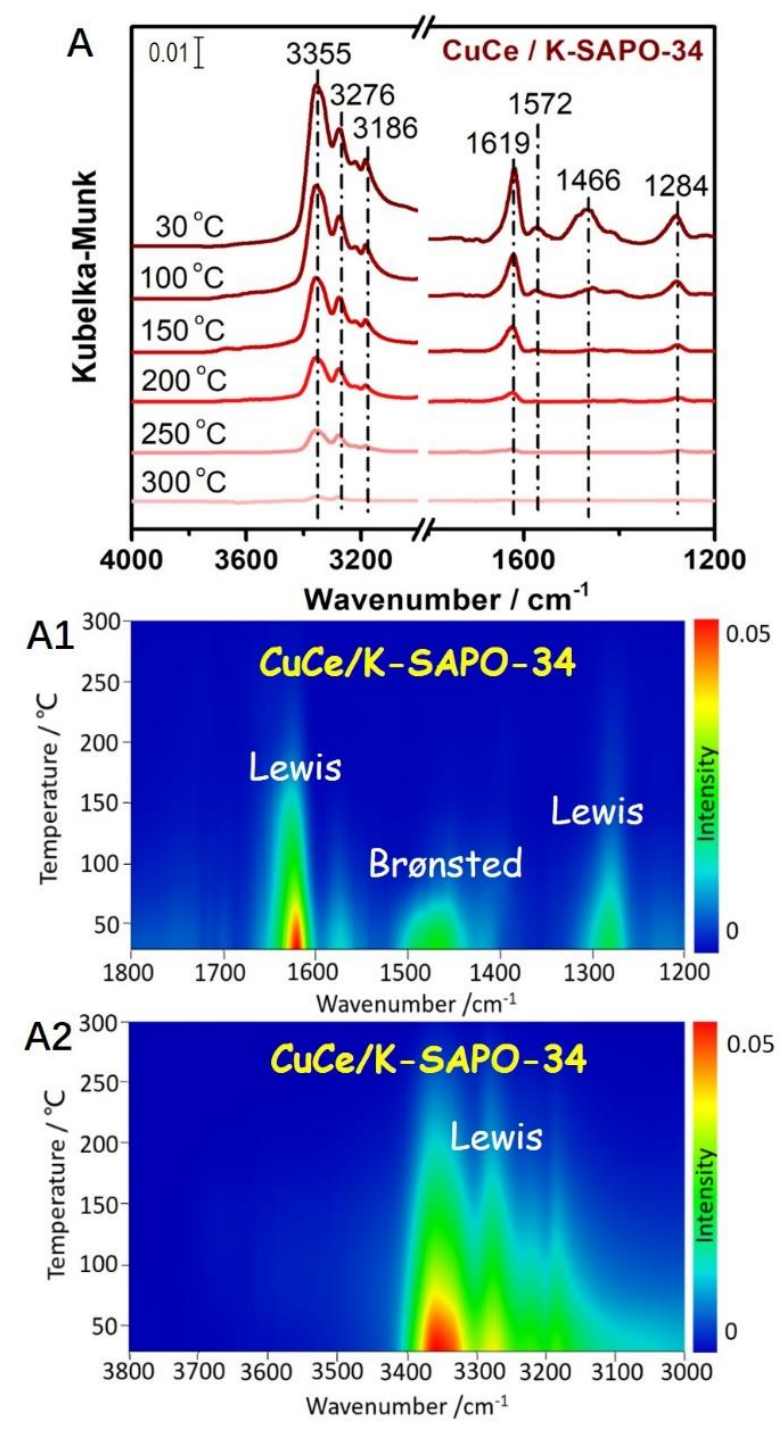

Figure S20. In situ DRIFTs spectra of (A) $\mathrm{NH}_{3}$ desorption desorption over $\mathrm{CuCe} / \mathrm{K}-\mathrm{SAPO}-34$ catalyst as a function of temperature after exposure to a flow of $500 \mathrm{ppm} \mathrm{NH}_{3}$ or $500 \mathrm{ppm} \mathrm{NO}+5 \% \mathrm{O}_{2}$ for 1 $\mathrm{h}$ at $30{ }^{\circ} \mathrm{C}$ and the corresponding mapping results in the range of (A1) $1200-1800 \mathrm{~cm}^{-1}$ and (A2) $3000-3800 \mathrm{~cm}^{-1}$.

Note: The type of acid sites for CuCe/K-SAPO-34 was not changed while the acidity intensity, especially the Brønsted acidity obviously declined compared with $\mathrm{CuCe} / \mathrm{H}-\mathrm{SAPO}-34$, which further declared that the Brønsted acid sites could be occupied by the $\mathrm{K}$ ions that exchanging firstly and impaired the SCR activity (Figure S20). 

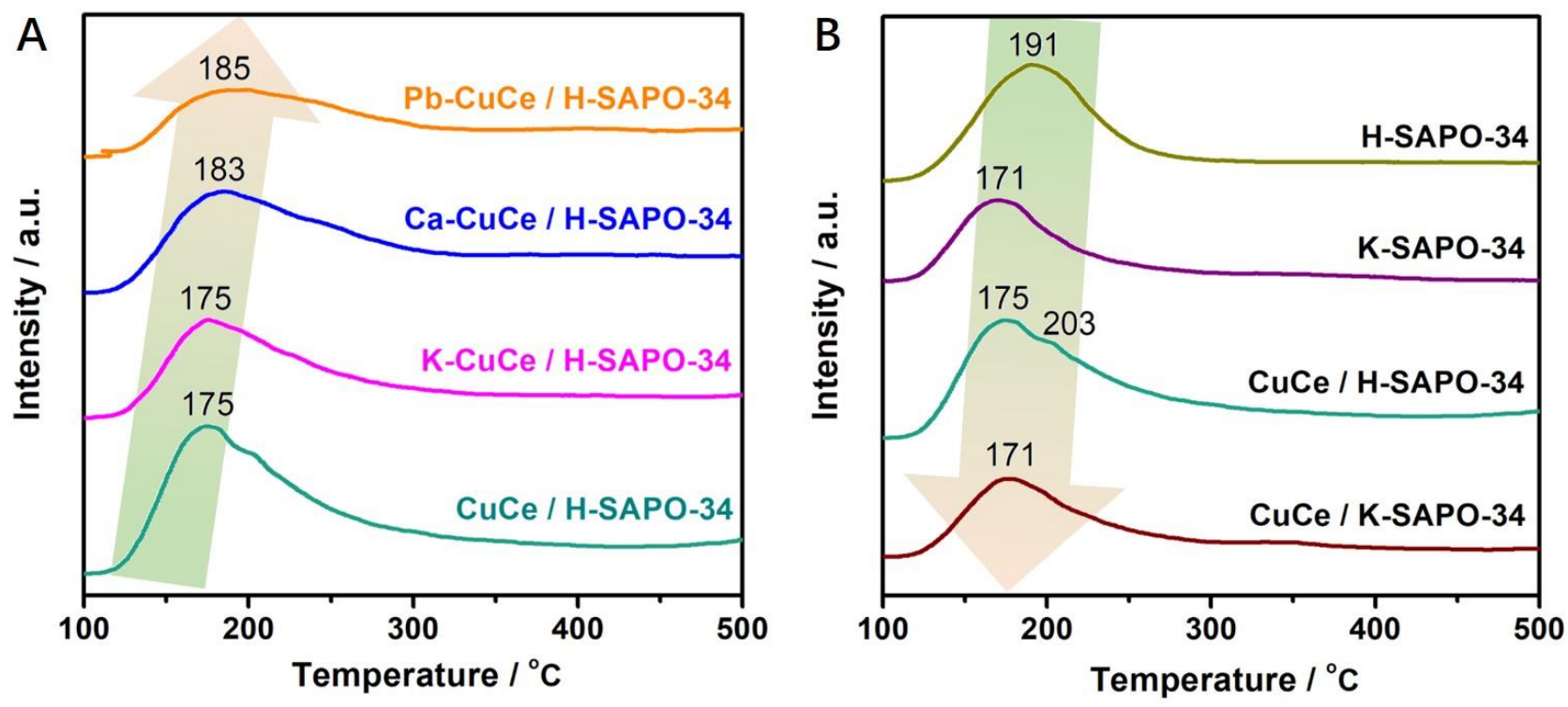

Figure S21. $\mathrm{NO}+\mathrm{O}_{2}-\mathrm{TPD}$ profiles of (A) $\mathrm{Cu} / \mathrm{H}-\mathrm{SAPO}-34$ and poisoned catalysts and (B) $\mathrm{H}-\mathrm{SAPO}-34$, K-SAPO-34, CuCe/H-SAPO-34, CuCe/K-SAPO-34 catalysts.

Note: The $\mathrm{CuCe} / \mathrm{H}-\mathrm{SAPO}-34$ catalyst had an obvious $\mathrm{NO}_{\mathrm{x}}$ desorption peak around $175{ }^{\circ} \mathrm{C}$. After poisoning, the desorption peak intensity declined slightly and the peak position was unchangeable for $\mathrm{K}-\mathrm{CuCe} / \mathrm{H}-\mathrm{SAPO}-34$ while shifted to higher temperature at 183 and $185^{\circ} \mathrm{C}$ for $\mathrm{Ca}-\mathrm{CuCe} / \mathrm{H}-\mathrm{SAPO}-$ 34 and $\mathrm{Pb}-\mathrm{CuCe} / \mathrm{H}-\mathrm{SAPO}-34$, respectively, indicating that $\mathrm{K}, \mathrm{Ca}, \mathrm{Pb}$ poisoning would slightly affect the $\mathrm{NO}_{\mathrm{x}}$ adsorption ability via bonding with active metal component or H-SAPO-34 support (Figure S21A). Similarly, K-SAPO-34 and CuCe/K-SAPO-34 both exhibited slight $\mathrm{NO}_{\mathrm{x}}$ desorption decline, which was also caused by the strong interaction of K with H-SAPO-34 support (Figure S21B). 

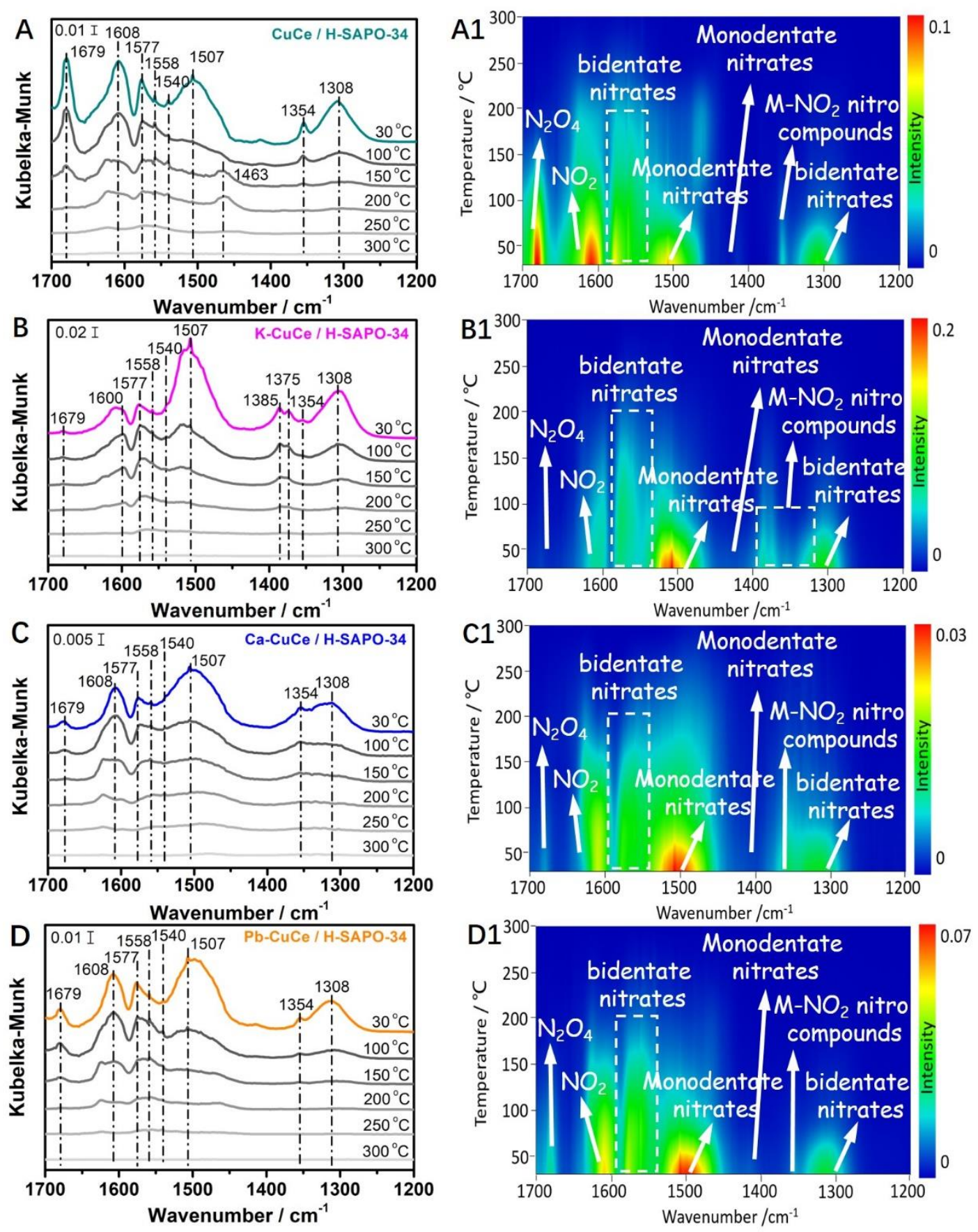

Figure S22. In situ DRIFTs spectra of $\mathrm{NO}+\mathrm{O}_{2}$ desorption and the corresponding mapping results over (A, A1) CuCe/H-SAPO-34, (B, B1) K-CuCe/H-SAPO-34, (C, C1) Ca-CuCe/H-SAPO-34, (D, D1) $\mathrm{Pb}-\mathrm{CuCe} / \mathrm{H}-\mathrm{SAPO}-34$ catalysts as a function of temperature after exposure to a flow of $500 \mathrm{ppm}$ $\mathrm{NO}+5 \% \mathrm{O}_{2}$ for $1 \mathrm{~h}$ at $30{ }^{\circ} \mathrm{C}$.

Note: The surface of $\mathrm{CuCe} / \mathrm{H}-\mathrm{SAPO}-34$ was covered with various $\mathrm{NO}_{\mathrm{x}}$ species after $\mathrm{NO}+\mathrm{O}_{2}$ was introduced, including bidentate nitrates $\left(1308,1540,1558 \text {, and } 1577 \mathrm{~cm}^{-1}\right)^{8-10}$, monodentate nitrates 
(1463 and $\left.1507 \mathrm{~cm}^{-1}\right)^{8}$, nitro compounds $\left(1354 \mathrm{~cm}^{-1}\right){ }^{10}, \mathrm{~N}_{2} \mathrm{O}_{4}\left(1679 \mathrm{~cm}^{-1}\right)^{11}$, and adsorbed $\mathrm{NO}_{2}$ $\left(1608 \mathrm{~cm}^{-1}\right)^{10}$ (Figure S22A). In the spectrum of the $\mathrm{K}-\mathrm{CuCe} / \mathrm{H}-\mathrm{SAPO}-34$ catalyst (Figure S22B), some new peaks (1375 and $1385 \mathrm{~cm}^{-1}$ ) assigned to nitro compounds and cis- $\mathrm{N}_{2} \mathrm{O}_{2}$ appeared, and the band intensities of $\mathrm{NO}_{\mathrm{x}}$ species in the K-poisoned catalyst were higher than those in the fresh catalyst (Figure S22A1 and B1). This verified that the introduction of new base sites by the K ions favored $\mathrm{NO}_{\mathrm{x}}$ adsorption. Furthermore, the introduction of $\mathrm{Ca}$ or $\mathrm{Pb}$ did not change the nitrate species adsorbed on the surface of catalysts but improved the intensity of some peaks (Figure S22C, D, C1, and D1). Generally, the adsorbed $\mathrm{NO}_{2}$ supplied the foundation for "fast" SCR ${ }^{11}$, and even after $\mathrm{K}, \mathrm{Ca}$, or $\mathrm{Pb}$ poisoning, the $\mathrm{NO}_{2}$ peak of the catalysts did not disappear, indicating that the dominant "fast" SCR step was not inhibited. 

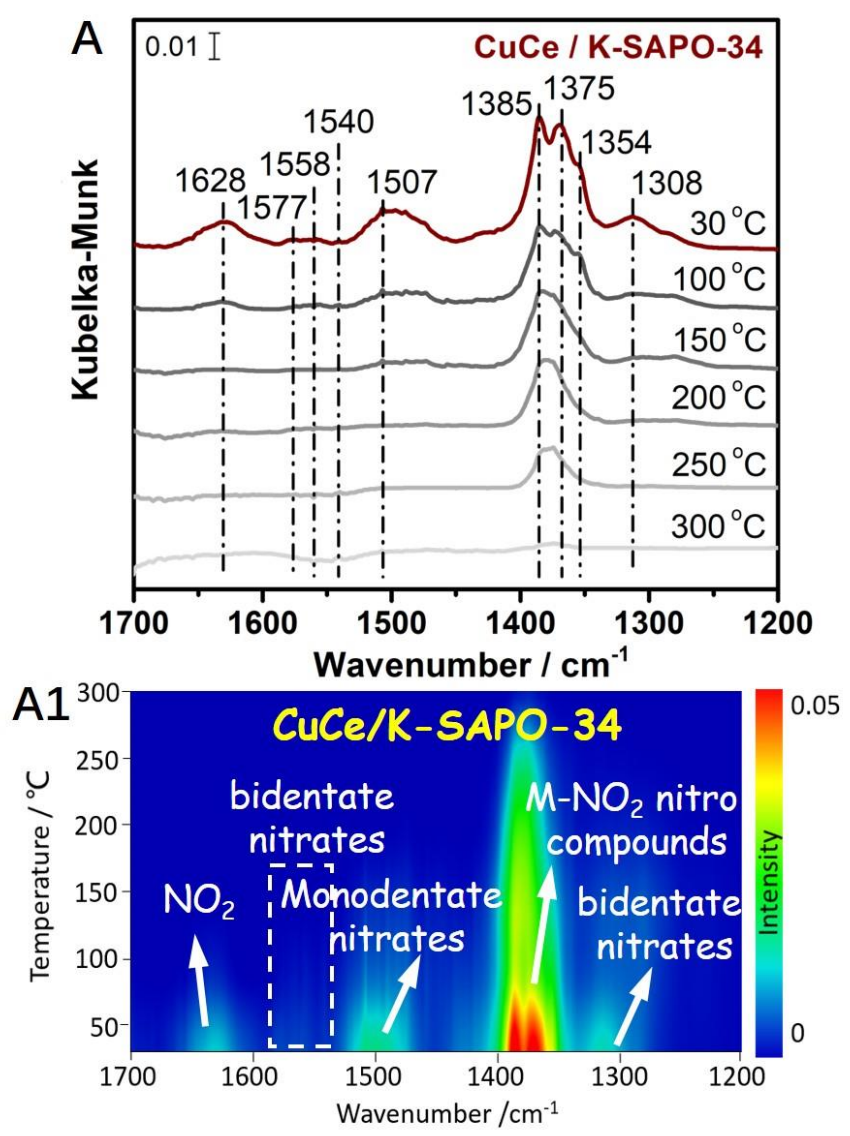

Figure S23. In situ DRIFTs spectra of (A) $\mathrm{NO}+\mathrm{O}_{2}$ desorption over CuCe/K-SAPO-34 catalyst as a function of temperature after exposure to a flow of $500 \mathrm{ppm} \mathrm{NH}_{3}$ or $500 \mathrm{ppm} \mathrm{NO}+5 \% \mathrm{O}_{2}$ for $1 \mathrm{~h}$ at $30{ }^{\circ} \mathrm{C}$ and the corresponding mapping results in the range of (A1) $1200-1700 \mathrm{~cm}^{-1}$.

Note: The surface of $\mathrm{CuCe} / \mathrm{K}-\mathrm{SAPO}-34$ was covered with various $\mathrm{NO}_{\mathrm{x}}$ species after $\mathrm{NO}+\mathrm{O}_{2}$ was introduced, including bidentate nitrates $\left(1308,1540,1558\right.$, and $\left.1577 \mathrm{~cm}^{-1}\right)$, monodentate nitrates $\left(1507 \mathrm{~cm}^{-1}\right)$, nitro compounds $\left(1354,1375 \mathrm{~cm}^{-1}\right)$, cis- $\mathrm{N}_{2} \mathrm{O}_{2}\left(1385 \mathrm{~cm}^{-1}\right)$, and adsorbed $\mathrm{NO}_{2}(1628$ $\mathrm{cm}^{-1}$ ) (Figure S23). Although some peak positions had changed compared with CuCe/H-SAPO-34, the $\mathrm{NO}_{\mathrm{x}}$ species and their intensities almost remained the same, claiming that the K-SAPO-34 might affect the $\mathrm{NO}_{\mathrm{x}}$ adsorbed sites and still accounted more for the surface acidity and $\mathrm{NH}_{3}$ adsorption. 

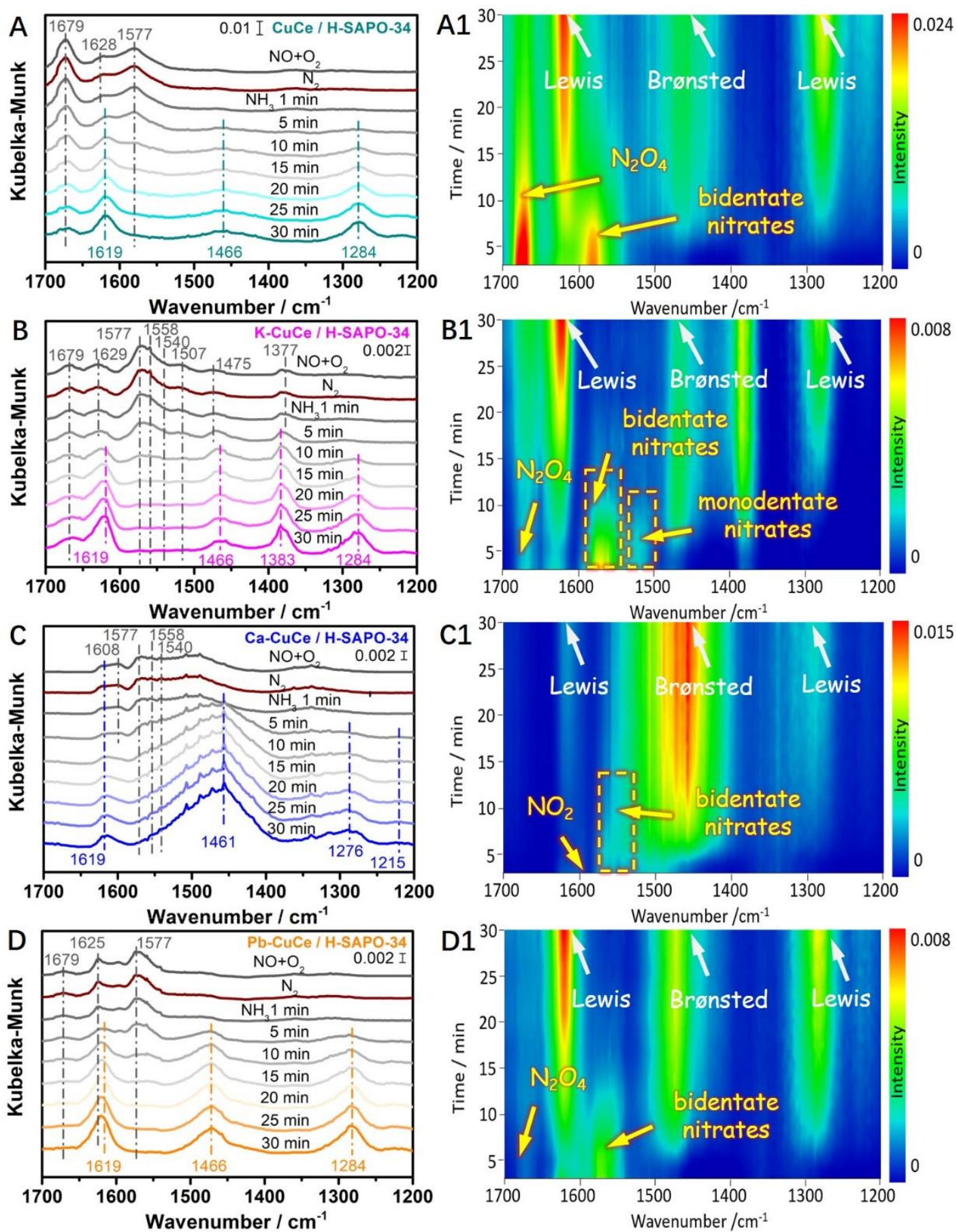

Figure S24. In situ DRIFTs spectra of the transient reactions at $200{ }^{\circ} \mathrm{C}$ and the corresponding mapping results over (A, A1) CuCe/H-SAPO-34 (B, B1) K-CuCe/H-SAPO-34, (C, C1) Ca-CuCe/H-SAPO-34 and $(\mathrm{D}, \mathrm{D} 1) \mathrm{Pb}-\mathrm{CuCe} / \mathrm{H}-\mathrm{SAPO}-34$ catalysts between $\mathrm{NH}_{3}$ and pre-adsorbed $\mathrm{NO}+\mathrm{O}_{2}$ as a function of time. 

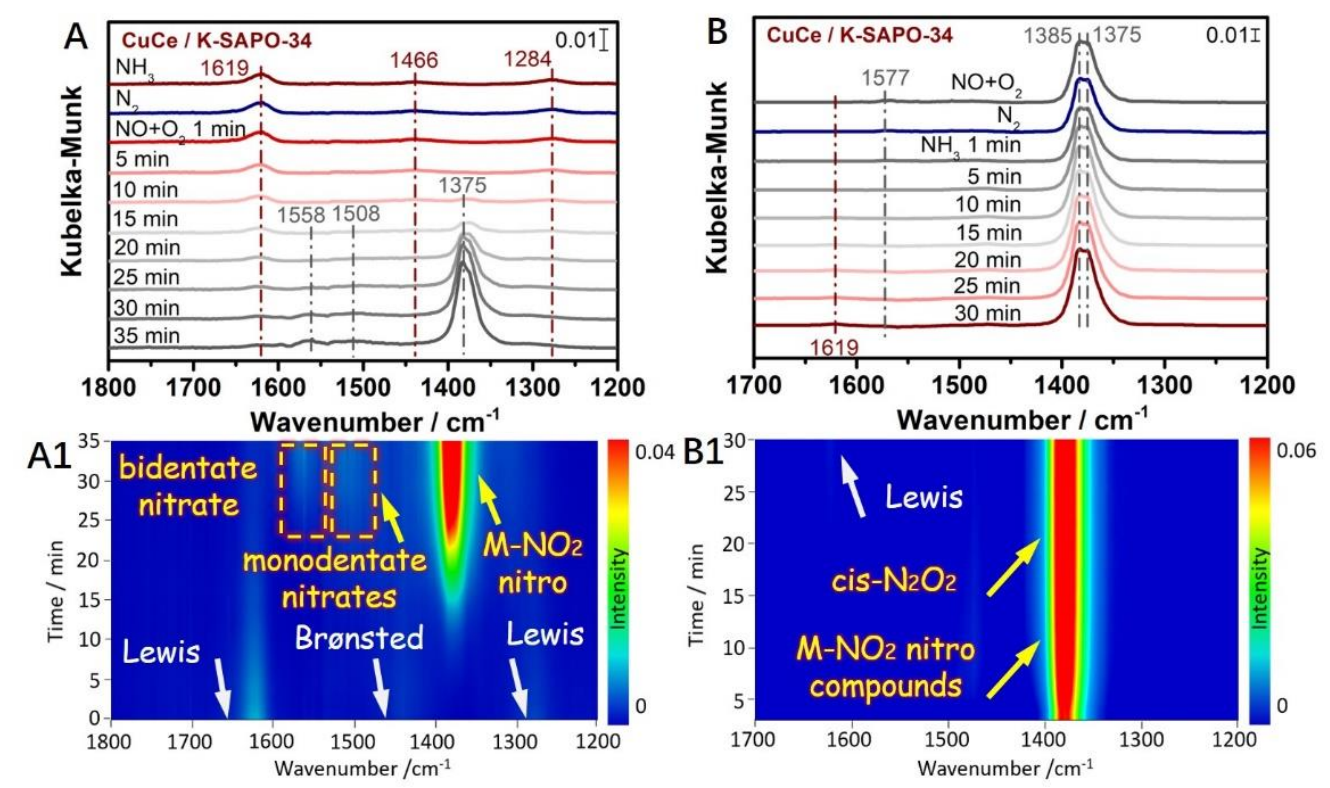

Figure S25. In situ DRIFTs spectra of the transient reactions at $200^{\circ} \mathrm{C}$ and the corresponding mapping results over $\mathrm{CuCe} / \mathrm{K}-\mathrm{SAPO}-34$ catalyst $(\mathrm{A}, \mathrm{A} 1)$ between $\mathrm{NO}+\mathrm{O}_{2}$ and pre-adsorbed $\mathrm{NH}_{3}$ and $(\mathrm{B}, \mathrm{B} 1)$ between $\mathrm{NH}_{3}$ and pre-adsorbed $\mathrm{NO}+\mathrm{O}_{2}$ as a function of time for the reaction.

Note: After exposure to $500 \mathrm{ppm} \mathrm{NH}_{3}$ for $1 \mathrm{~h}$, the surface adsorbed ammonia species mainly included coordinated $\mathrm{NH}_{3}$ bound to Lewis acid sites $\left(1619\right.$ and $\left.1284 \mathrm{~cm}^{-1}\right)$ and ionic $\mathrm{NH}_{4}^{+}$bound to Brønsted acid sites $\left(1466 \mathrm{~cm}^{-1}\right)$. When $\mathrm{NO}$ and $\mathrm{O}_{2}$ were introduced, the peaks of coordinated $\mathrm{NH}_{3}$ and $\mathrm{NH}_{4}^{+}$ were gradually consumed, and several peaks belonging to $\mathrm{M}-\mathrm{NO}_{2}$ nitro compounds $\left(1375 \mathrm{~cm}^{-1}\right)$, monodentate nitrates $\left(1508 \mathrm{~cm}^{-1}\right)$, bidentate nitrate species $\left(1558 \mathrm{~cm}^{-1}\right)$ gradually appeared at $15 \mathrm{~min}$ (Figure S25A and A1). After reversing the sequence of gases, it was observed that the surface of $\mathrm{CuCe} / \mathrm{K}-\mathrm{SAPO}-34$ was covered by nitro compounds and cis- $\mathrm{N}_{2} \mathrm{O}_{2}\left(1385 \mathrm{~cm}^{-1}\right)$ species. After the introduction of $\mathrm{NH}_{3}$, the $\mathrm{NO}_{x}$ species still remained the same and could not participate into the reaction, which named as inactive species (Figure S25B and B1). These results proved the replacement of HSAPO-34 support by K-SAPO-34 not only impaired the $\mathrm{NH}_{3}$ adsorption and also restrained the SCR reaction, claiming again the unique role of H-SAPO-34 support with abundant Brønsted acid sites. 
Table S1. The $\mathrm{Cu}$ and $\mathrm{Ce}$ content of fresh and poisoned $\mathrm{CuCe} / \mathrm{H}-\mathrm{SAPO}-34$ catalysts obtained from ICP results.

\begin{tabular}{ccc}
\hline Catalysts & Cu (wt\%) & Ce (wt\%) \\
\hline $\mathrm{Cu} / \mathrm{H}-\mathrm{SAPO}-34$ & 9.885 & $/$ \\
$\mathrm{CuCe} / \mathrm{H}-\mathrm{SAPO}-34$ & 9.865 & 4.920 \\
$\mathrm{~K}-\mathrm{CuCe} / \mathrm{H}-\mathrm{SAPO}-34$ & 9.850 & 4.895 \\
$\mathrm{Ca}-\mathrm{CuCe} / \mathrm{H}-\mathrm{SAPO}-34$ & 9.825 & 4.860 \\
$\mathrm{~Pb}-\mathrm{CuCe} / \mathrm{H}-\mathrm{SAPO}-34$ & 9.805 & 4.855 \\
\hline
\end{tabular}


Table S2. Textural parameters of the catalysts obtained from $\mathrm{N}_{2}$ adsorption-desorption experiments.

\begin{tabular}{llll}
\hline Catalysts & $\begin{array}{l}\text { Specific surface area } \\
\left(\mathbf{m}^{\mathbf{2}} \mathbf{g}^{-\mathbf{1}}\right)\end{array}$ & $\begin{array}{l}\text { Pore diameter } \\
(\mathbf{n m})\end{array}$ & $\begin{array}{l}\text { Pore volume } \\
\left(\mathbf{c m}^{\mathbf{3}} \mathbf{g}^{-\mathbf{1}}\right)\end{array}$ \\
\hline $\mathrm{H}-\mathrm{SAPO}-34$ & 550 & 2.02 & 0.28 \\
$\mathrm{CuCe}(3) / \mathrm{H}-\mathrm{SAPO}-34$ & 42 & 2.99 & 0.03 \\
$\mathrm{CuCe}(5) / \mathrm{H}-\mathrm{SAPO}$ & 50 & 2.96 & 0.04 \\
$\mathrm{CuCe}(7) / \mathrm{H}-\mathrm{SAPO}-34$ & 59 & 2.63 & 0.04 \\
$\mathrm{~K}-\mathrm{CuCe} / \mathrm{H}-\mathrm{SAPO}-34$ & 135 & 2.33 & 0.08 \\
$\mathrm{Ca}-\mathrm{CuCe} / \mathrm{H}-\mathrm{SAPO}-34$ & 104 & 2.38 & 0.06 \\
$\mathrm{~Pb}-\mathrm{CuCe} / \mathrm{H}-\mathrm{SAPO}-34$ & 28 & 3.92 & 0.03 \\
\hline
\end{tabular}

Note: The surface area of H-SAPO-34 was $550 \mathrm{~m}^{2} \mathrm{~g}^{-1}$ and decreased after loading $\mathrm{Cu}$ and $\mathrm{Ce}$, which was due to the coverage of $\mathrm{Cu}$ and $\mathrm{Ce}$. Furthermore, the surface areas of $\mathrm{CuCe}(\mathrm{y}) / \mathrm{H}-\mathrm{SAPO}-34$ with the ratio of $\mathrm{Ce}=0,3,5 \mathrm{wt} \%$ particularly increased as the Ce amount increased. Generally, the surface area of samples after poisoning would decrease, which was caused by occupying or blocking the active sites. However, in our work, the surface area of $\mathrm{K}-\mathrm{CuCe} / \mathrm{H}-\mathrm{SAPO}-34\left(135 \mathrm{~m}^{2} \mathrm{~g}^{-1}\right)$ and $\mathrm{Ca}-\mathrm{CuCe} / \mathrm{H}-$ SAPO-34 $\left(104 \mathrm{~m}^{2} \mathrm{~g}^{-1}\right)$ increased when compared with CuCe/H-SAPO-34 $\left(50 \mathrm{~m}^{2} \mathrm{~g}^{-1}\right)$. This might be due to the second calcination during the poisoning process increased the crystallinity of surface oxides and exposed more channels of H-SAPO-34, which created more opportunities for alkaline metals to be trapped by H-SAPO-34. Meanwhile, $\mathrm{K}$ or $\mathrm{Ca}$ formed oxides in the calcining process, destroying the situation that most channels had been covered by $\mathrm{Ce}$ and $\mathrm{Cu}$ in $\mathrm{CuCe} / \mathrm{H}-\mathrm{SAPO}-34$ catalyst and making the poisoned catalyst had larger surface area. Nevertheless, $\mathrm{Pb}$ showed obviously negative effect on the surface area and made it decrease to $28 \mathrm{~m}^{2} \mathrm{~g}^{-1}$. This could be attributed to H-SAPO-34 was not as attractive to $\mathrm{Pb}$ and only a small amount of $\mathrm{Pb}$ could be captured into H-SAPO-34. In consequence, most of $\mathrm{Pb}$ would be bonded to the surface $\mathrm{Ce}$ to further reduce the surface area. 
Table S3. The valence distribution of catalysts obtained from the fitted XPS spectra.

\begin{tabular}{llll}
\hline & \multicolumn{3}{c}{ Atomic ratio } \\
\cline { 2 - 4 } Catalysts & $\mathbf{C u}^{2+} /\left(\mathbf{C u}^{+}+\mathbf{C u}^{2+}\right)$ & $\mathbf{C e}^{3+} /\left(\mathbf{C e}^{4+}+\mathbf{C e}^{3+}\right)$ & $\mathbf{O}_{\boldsymbol{\alpha}} /\left(\mathbf{O}_{\boldsymbol{\beta}}+\mathbf{O}_{\boldsymbol{\alpha}}\right)$ \\
& $(\%)$ & $(\%)$ & $(\%)$ \\
\hline $\mathrm{CuCe} / \mathrm{\%}-\mathrm{\%})$ & 24.77 & 61.17 \\
$\mathrm{~K}-\mathrm{CuCe} / \mathrm{H}-\mathrm{SAPO}-34$ & 53.51 & 24.38 & 60.58 \\
$\mathrm{Ca}-\mathrm{CuCe} / \mathrm{H}-\mathrm{SAPO}-34$ & 53.21 & 21.11 & 59.02 \\
$\mathrm{~Pb}-\mathrm{CuCe} / \mathrm{H}-\mathrm{SAPO}-34$ & 53.11 & 20.11 & 59.38 \\
\hline
\end{tabular}




\section{REFERENCES}

1. Chen, L.; Si, Z.; Wu, X.; Weng, D., DRIFT Study of $\mathrm{CuO}-\mathrm{CeO}_{2}-\mathrm{TiO}_{2}$ Mixed Oxides for $\mathrm{NO}_{\mathrm{x}}$ Reduction with $\mathrm{NH}_{3}$ at Low Temperatures. ACS Appl. Mater. Interfaces 2014, 6, (11), 8134-8145.

2. Liu, J.; Shi, X.; Shan, Y.; Yan, Z.; Shan, W.; Yu, Y.; He, H., Hydrothermal Stability of $\mathrm{CeO}_{2}-\mathrm{WO}_{3}-\mathrm{ZrO}_{2} \mathrm{Mixed}$ Oxides for Selective Catalytic Reduction of $\mathrm{NO}_{\mathrm{x}}$ by $\mathrm{NH}_{3}$. Environ. Sci. Technol. 2018, 52, (20), 11769-11777.

3. Bhavani, A.; Kim, W.; Lee, J., Barium Substituted Lanthanum Manganite Perovskite for $\mathrm{CO}_{2}$ Reforming of Methane. ACS Catal. 2013, 3, (7), 1537-1544.

4. Kang, L.; Han, L.; He, J.; Li, H.; Yan, T.; Chen, G.; Zhang, J.; Shi, L.; Zhang, D., Improved $\mathrm{NO}_{\mathrm{x}}$ Reduction in the Presence of $\mathrm{SO}_{2}$ by Using $\mathrm{Fe}_{2} \mathrm{O}_{3}$-Promoted Halloysite-Supported $\mathrm{CeO}_{2}-\mathrm{WO}_{3}$ Catalysts. Environ. Sci. Technol. 2019, 53, (2), 938-945.

5. Michalow-Mauke, K.; Lu, Y.; Kowalski, K.; Graule, T.; Nachtegaal, M.; Kröcher, O.; Ferri, D., Flame-Made $\mathrm{WO}_{3} / \mathrm{CeO}_{\mathrm{x}}-\mathrm{TiO}_{2}$ Catalysts for Selective Catalytic Reduction of $\mathrm{NO}_{\mathrm{x}}$ by $\mathrm{NH}_{3}$. ACS Catal. 2015, 5, (10), 5657-5672.

6. Sun, S.; Mao, D.; Yu, J.; Yang, Z.; Lu, G.; Ma, Z., Low-Temperature CO Oxidation on $\mathrm{CuO} / \mathrm{CeO}_{2}$ Catalysts: the Significant Effect of Copper Precursor and Calcination Temperature. Catal. Sci. Technol. 2015, 5, (6), 3166-3181.

7. Zhang, L.; Shi, L.; Huang, L.; Zhang, J.; Gao, R.; Zhang, D., Rational Design of High-Performance DeNO Catalysts Based on $\mathrm{Mn}_{\mathrm{x}} \mathrm{Co}_{3-\mathrm{x}} \mathrm{O}_{4}$ Nanocages Derived from Metal-Organic Frameworks. ACS Catal. 2014, 4, (6), 1753-1763.

8. Gao, F.; Tang, X.; Yi, H.; Li, J.; Zhao, S.; Wang, J.; Chu, C.; Li, C., Promotional Mechanisms of Activity and $\mathrm{SO}_{2}$ Tolerance of Co- or Ni-Doped $\mathrm{MnO}_{\mathrm{x}}-\mathrm{CeO}_{2}$ Catalysts for SCR of $\mathrm{NO}_{\mathrm{x}}$ with $\mathrm{NH}_{3}$ at Low Temperature. Chem. Eng. J. 2017, 317, 20-31.

9. Wang, D.; Zhang, L.; Kamasamudram, K.; Epling, W., In Situ-DRIFTS Study of Selective Catalytic Reduction of $\mathrm{NO}_{\mathrm{x}}$ by $\mathrm{NH}_{3}$ over Cu-Exchanged SAPO-34. ACS Catal. 2013, 3, (5), 871-881.

10. Liu, Z.; Su, H.; Li, J.; Li, Y., Novel $\mathrm{MoO}_{3} / \mathrm{CeO}_{2}-\mathrm{ZrO}_{2}$ Catalyst for the Selective Catalytic Reduction of $\mathrm{NO}_{\mathrm{x}}$ by $\mathrm{NH}_{3}$. Catal. Commun. 2015, 65, 51-54.

11. Wang, H.; Qu, Z.; Dong, S.; Xie, H.; Tang, C., Superior Performance of $\mathrm{Fe}_{1-\mathrm{x}} \mathrm{W}_{\mathrm{x}} \mathrm{O}_{\delta}$ for the Selective Catalytic Reduction of $\mathrm{NO}_{x}$ with $\mathrm{NH}_{3}$ : Interaction between Fe and W. Environ. Sci. Technol. 2016, 50, (24), 13511-13519. 